\title{
Resource
}

\section{Multi-omics analysis of xylem sap uncovers dynamic modulation of poplar defenses by ammonium and nitrate}

Karl Kasper ${ }^{1}$, Ilka N Abreu², Kirstin Feussner ${ }^{2,3}$, Krzysztof Zienkiewicz ${ }^{2}$, Cornelia Herrfurth ${ }^{2,3}$, Till Ischebeck ${ }^{2}$, Dennis Janz ${ }^{1}$, Andrzej Majcherczyk ${ }^{4}$, Kerstin Schmitt ${ }^{5,6}$, Oliver Valerius ${ }^{5,6}$, Gerhard H. Braus ${ }^{5,6}$, Ivo Feussner ${ }^{2,3}$, Andrea Polle ${ }^{1^{*}}$

Karl Kasper (ORCID iD: 0000-0002-6020-8829)

Ilka N Abreu (ORCID iD: 0000-0003-4728-0161)

Kirstin Feussner (ORCID iD: 0000-0003-1634-8258)

Ivo Feussner (ORCID iD: 0000-0002-9888-7003)

Andrea Polle (ORCID iD: 0000-0001-8697-6394)

*correspondence: A. Polle, email: apolle@gwdg.de

${ }^{1}$ Forest Botany and Tree Physiology, Goettingen Center for Molecular Biosciences (GZMB), University of Goettingen, Büsgenweg 2, 37077 Goettingen, Germany

${ }^{2}$ Department of Plant Biochemistry, Albrecht-von-Haller-Institute for Plant Sciences and Goettingen Center for Molecular Biosciences (GZMB), University of Goettingen, Justus-vonLiebig-Weg 11, 37077 Goettingen, Germany

${ }^{3}$ Service Unit for Metabolomics and Lipidomics, Goettingen Center for Molecular Biosciences (GZMB), University of Goettingen, Justus-von-Liebig-Weg 11, 37077 Goettingen, Germany

${ }^{4}$ Molecular Wood Biotechnology and Technical Mycology, University of Goettingen, Büsgenweg 2, 37077 Göttingen

${ }^{5}$ Molecular Microbiology \& Genetics, Institute for Microbiology and Genetics and Goettingen Center for Molecular Biosciences (GZMB), University of Goettingen, Grisebachstr. 8, 37077 Göttingen, Germany

${ }^{6}$ Service Unit for Proteomics, Goettingen Center for Molecular Biosciences (GZMB), University of Goettingen, Grisebachstr. 8, 37077 Goettingen, Germany

Running title: Xylem sap omics uncovers defense modulation by nitrogen 
bioRxiv preprint doi: https://doi.org/10.1101/2021.05.28.446139; this version posted May 28, 2021. The copyright holder for this preprint (which was not certified by peer review) is the author/funder, who has granted bioRxiv a license to display the preprint in perpetuity. It is made available under aCC-BY-NC-ND 4.0 International license.

Keywords: carbohydrates, endophyte, metabolomics, nitrogen, phytohormones, proteomics, salicinoids, transcriptomics

\section{Significance statement}

This study reports the largest, currently available plant xylem sap proteome and metabolome databases and highlights novel discoveries of specialized metabolites and phytohormones in the xylem sap. This is the first multi-omics study linking differences in nitrogen supply with changes xylem sap composition, endophyte growth and transcriptional defenses in leaves. 


\section{Summary}

Xylem sap is the major transport route for nutrients from roots to shoots. Here, we investigated how variations in nitrogen $(\mathrm{N})$ nutrition affected the metabolome and proteome of xylem sap, growth of the xylem endophyte Brennaria salicis and report transcriptional rewiring of leaf defenses in poplar (Populus $x$ canescens). We supplied poplars with high, intermediate or low concentrations of ammonium or nitrate. We identified 288 unique proteins in xylem sap. About $85 \%$ of the xylem sap proteins were shared among ammoniumand nitrate-supplied plants. The number of proteins increased with increasing $\mathrm{N}$ supply but the major functional categories (catabolic processes, cell wall-related enzymes, defense) were unaffected. Ammonium nutrition caused higher abundances of amino acids and carbohydrates, while nitrate caused higher malate levels in xylem sap. Pipecolic acid and $N$ hydroxy-pipecolic acid increased whereas salicylic acid and jasmonoyl-isoleucine decreased with increasing $\mathrm{N}$ nutrition. Untargeted metabolome analyses revealed 2179 features in xylem sap, of which 863 were differentially affected by $N$ treatments. We identified 122 metabolites, mainly from specialized metabolism of the groups of salicinoids, phenylpropanoids, phenolics, flavonoids, and benzoates. Their abundances increased with decreasing N. Endophyte growth was stimulated in xylem sap of high $\mathrm{N}$ - and suppressed in that of low $\mathrm{N}$-fed plants. The drastic changes in xylem sap composition caused massive changes in the transcriptional landscape of leaves and recruited defense pathways against leaf feeding insects and biotrophic fungi, mainly under low nitrate. Our study uncovers unexpected complexity and variability of xylem composition with consequences for plant defenses. 


\section{Introduction}

Nitrogen $(\mathrm{N})$ is a key plant nutrient, required for biosynthesis of amino acids, proteins, nucleic acids, and for many other essential metabolic functions. In soil, the dominant forms available for plant nutrition are nitrate and ammonium (Marschner, 2011). Their concentrations in the environment are highly variable, depending for example on soil type, microbial $\mathrm{N}$ turn-over, and atmospheric deposition (Nie et al., 2017). In undisturbed forests, $\mathrm{N}$ is often a limiting factor for tree growth, requiring N cycling within the ecosystem (Schimel and Bennett, 2004); Rennenberg \& Dannenmann, 2015). Degradation and mineralization of organically bound N result in the oxidized form $\mathrm{NO}_{3}{ }^{-}$, which is then reduced to ammonium $\left(\mathrm{NH}_{4}{ }^{+}\right)$by microbial activities; $\mathrm{NH}_{4}{ }^{+}$is, thus, generally the main $\mathrm{N}$ source for forest trees, whereas in ruderal and riparian sites, $\mathrm{NO}_{3}^{-}$is the major form taken up by trees (Rennenberg et al., 2009). Anthropogenic activities, especially intense crop and livestock production have increased $\mathrm{N}$ deposition across Europe (Morseletto, 2019; Stevens, 2019). Large-scale N deposition has also increased in many forest regions (Rennenberg \& Dannenmann, 2015). Excess $N$ deposition results in an enhanced release of the greenhouse gas $\mathrm{N}_{2} \mathrm{O}$ to the atmosphere (Merbach et al., 1996) and enhances $\mathrm{NO}_{3}{ }^{-}$input and soil acidification with adverse effects on tree health and forest biodiversity (Jandl et al., 2012). It is, therefore, important to better understanding how tree species cope with varying $\mathrm{N}$ availabilities in the environment.

Nitrogen is taken up by plant roots, metabolized and transported via the xylem sap to the leaves for further metabolization (Marschner, 2011). The consequences of variations in nitrate or ammonium nutrition have been studied in leaves and roots showing, for example, stronger responses to ammonium than to nitrate depletion in Arabidopsis leaves (Menz et al., 2016). N transport in xylem sap has been studied in tree species focusing mainly on amino acids, nitrate, and ammonium (e.g., Gessler et al., 1998, 2004; Kato, 1981; Siebrecht \& Tischner, 1999; Tromp \& Ovaa, 1976; Weber et al., 1998). Poplar (Populus x canescens) xylem sap contains approximately $3 \mathrm{mM}$ nitrate and up to $15 \mathrm{mM}$ glutamine, when fed with $1 \mathrm{mM} \mathrm{NO}_{3}{ }^{-}$ in hydroponics (Siebrecht and Tischner, 1999). After switching from nitrate to ammonium nutrition, nitrate concentrations in the xylem sap of poplar drop quickly and $\mathrm{NH}_{4}{ }^{+}$levels increase (Siebrecht and Tischner, 1999). In addition to mineral nutrients and amino acids, xylem sap also contains a huge array of proteins with roles in cell wall formation and defense (Dafoe and Constabel, 2009; Pechanova et al., 2010). However, comprehensive analyses, if 
and how changes in ammonium or nitrate availabilities influence the metabolome and proteome of the xylem sap are lacking.

Ecological studies reported that $\mathrm{N}$ nutrition affects the balance between growth and defense, thereby, interfering with biotic stress tolerance (Harding et al., 2009; Manninen et al., 1998; Nerg et al., 2008; Rubert-Nason et al., 2015). For example, high $\mathrm{N}$ availability results in decreased tannin concentrations in poplar leaves (Madritch and Lindroth, 2015) and enhanced development of the leaf feeding larvae of Choristoneura conflictana (Bryant et al., 1987). In various agricultural crops, infections with fungal pathogens decreased under low and increased under high $\mathrm{N}$ supply (Mur et al., 2017), suggesting that information conveyed by the xylem sap from roots to leaves has consequences for foliar defense systems.

The main aims of the present work were a comprehensive characterization of the metabolome and proteome of $P$. $x$ canescens xylem sap in response to increasing $N$ supplied either as nitrate or as ammonium. A further important goal was to investigate the responses of the leaf defense transcriptome to changes in $\mathrm{N}$ supply. For this purpose, $P . \mathrm{x}$ canescens were supplied with low $(0.4 \mathrm{mM})$, medium $(2 \mathrm{mM})$, or high concentrations $(8 \mathrm{mM})$ of $\mathrm{NH}_{4}{ }^{+}$or $\mathrm{NO}_{3}{ }^{-}$. The composition of the xylem sap in response to these changes in $\mathrm{N}$ supply was extensively characterized, resulting in the largest libraries for poplar xylem sap metabolome and proteome data available to date. We report for the first time pipecolic acid and $\mathrm{N}$-hydroxypipecolic acid (NHP) in xylem sap and their differences under ammonium and nitrate nutrition. Changes in nitrate and ammonium concentrations also had divergent effects on the xylem sap composition of amino acids, carbohydrates, organic acids, secondary compounds, and phytohormones. Protein diversity in the xylem sap increased with increasing $\mathrm{N}$ supply. We tested the impact of these changes for poplar susceptibility to biotic stress in the vascular system employing bioassays with the gram-negative bacterium Brennaria salicis (formerly Erwinia salicis). B. salicis lives as an endophyte in the xylem of Populus spp. (Maes et al., 2009) and is the causal agent of the watermark disease in Salix spp. (Day, 1924; Huvenne et al., 2009). By bioinformatic comparison of poplar leaf transcriptomes against poplar rust (Melamspora spp., Luo et al., 2019; Miranda et al., 2007; Rinaldi et al., 2007) and herbivory (Chrysomela populi, Kaling et al., 2018), we found low-nitrate driven activation of salicylic acid (SA)- and jasmonate (JA)-related defenses. 


\section{Results}

\section{Ammonium and nitrate differentially shape primary metabolite composition in xylem sap}

Feeding poplars with nitrate or ammonium strongly affected the concentrations of these nutrients in poplar xylem sap (Table 1). The concentrations of $\mathrm{NO}_{3}{ }^{-}$increased with increasing nitrate and of $\mathrm{NH}_{4}^{+}$with increasing ammonium supply (Table 1). The highest protein concentrations occurred in xylem sap of plants fed with high ammonium (Table 1). In agreement with other poplar studies (Euring et al., 2014; Gan et al., 2015; Reichardt et al., 1991), increasing $N$ supply resulted in enhanced photosynthesis, growth, biomass, and increased tissue concentrations of N (Supporting Table S1, Supporting Figure S1).

Intermediate and high ammonium nutrition further resulted in high amino acid concentrations in the xylem sap, whereas the increases in amino acids were less pronounced under high nitrate nutrition (Figure 1a, Supporting Table S2). The main amino acids detected under the current measuring conditions were derived from glutamate. Since glutamine and glutamate spontaneously cyclized to pyroglutamate during GC-MS sample preparation (Supporting Figure S2), the contributions of those individual compounds to xylem sap amino acids cannot be distinguished here. Taken together, glutamine and glutamate accumulated more than twelve-fold under high compared to low ammonium supply but only up to six-fold under high compared to low nitrate supply. Other studies found that glutamine is the major amino acid in poplar xylem sap (Dickson et al., 1985; Siebrecht \& Tischner, 1999).

Furthermore, ammonium and nitrate nutrition caused alterations in carbon-bearing compounds in the xylem sap: soluble carbohydrate levels were approximately twofold higher in high ammonium- than in high nitrate-fed plants (Figure 1b). Soluble organic acids were generally higher under nitrate than under ammonium nutrition, resulting in approximately five-fold increases in xylem sap of high nitrate- compared to that of high ammonium-fed plants (Figure 1c). Fructose and glucose were the most prominent carbohydrates and malate the most abundant organic acid in xylem sap (Figure 1 b,c).

\section{Ammonium- and nitrate-feeding impact phytohormones in the xylem sap}

We detected SA, SA-glucoside (SAG), jasmonoyl-isoleucine (JA-Ile), pipecolic acid, NHP, and abscisic acid (ABA) in poplar xylem sap (Figure 2). SA, SAG, JA-lle, pipecolic acid and NHP are 
involved in regulating plant defense responses (Antico et al., 2012; Bernsdorff et al., 2016; Y.,C., Chen et al., 2018; Schuman et al., 2018; Vlot et al., 2009). Xylem sap of low ammonium-fed poplars contained the highest concentrations of SA, SAG, and JA-Ile (Figure 2a,b,c). The concentrations of these phytohormones decreased with increasing $\mathrm{N}$ concentrations and were generally higher in ammonium- than in nitrate-fed plants. On the contrary, pipecolic acid and NHP increased with increasing $\mathrm{NH}_{4}{ }^{+}$supply (Figure $2 \mathrm{~d}$,e). Xylem sap of high ammoniumfed poplars contained the highest pipecolic acid and NHP levels, whereas NHP was not significantly affected by low and medium, and not detected under high nitrate supply (Figure $2 d, e)$. ABA, which is important to coordinate the plant's stature and acclimation to drought (Fujita et al., 2005; Yu et al., 2019), was unaffected by differences in $\mathrm{N}$ supply in poplar xylem sap (Figure 2f).

\section{Defense metabolites increase in poplar xylem sap under low nitrogen supply}

Next, we aimed to obtain a global overview on changes of xylem sap metabolites in response to $\mathrm{N}$ nutrition of poplar using a non-targeted metabolome approach. Alterations in the abundance of specialized metabolites, which had not been covered by the analyses shown so far, were of special interest in this experiment. In total, 2179 metabolite features were obtained by the non-targeted approach, a number that was reduced to 863 by filtering the data by a false discovery rate FDR $<10^{-6}$ (Supportive data file S1, Supporting Figure S3). A sample-based principal component analysis (PCA) for these selected features discriminated the samples along PC1 according to the N concentrations and along PC2 according to the N form (ammonium or nitrate) supplied to the plants (Figure 3a). Feature-based clustering by one-dimensional self-organizing maps was used for a general overview on the intensity patterns of the selected features (Supporting Figure S4). The heat map representation of the data in the self-organizing maps showed that each of the six nutrient treatments was characterized by a specific response pattern of metabolite features in the xylem sap, depending on the $\mathrm{N}$ form as well as on the $\mathrm{N}$ concentration supplied to the plants (Supporting Figure S4). The heat map indicated that a large number of features increased with decreasing $\mathrm{N}$ supply, irrespective of the $\mathrm{N}$ form, whereas the number of features strongly increasing with increasing $\mathrm{N}$ supply was higher in xylem sap of ammonium (about 180 features) than in that of nitrate-fed poplars (12 features, Supporting Figure S4). 
To determine the chemical identity of the compounds, represented by the features in the data set, the accurate mass information of the features was used for data base search and LCHRMS/MS fragmentation analyses were conducted. By this approach, the identities of 75 specialized metabolites were determined in the xylem sap of poplar (Supportive data file S2). Compounds involved in poplar defense (Boeckler et al., 2011; Chedgy et al., 2015), like salicinoids, phenylpropanoids, flavonoids, and benzoates (Figure 3b) were identified. Among the identified classes of secondary metabolites, salicinoids and benzoates accounted for the highest accumulated signal intensities (Figure $3 \mathrm{~b}$ ). Overall, the relative abundances of the specialized metabolites decreased with increasing $\mathrm{N}$ supply, with the exception of coumarins, which were differently affected by $\mathrm{N}$ treatments (Figure $3 \mathrm{~b}$ ) and exhibited lowest values under low $\mathrm{NH}_{4}{ }^{+}$and all $\mathrm{NO}_{3}{ }^{-}$treatments $(p<0.001)$. Among the salicinoids, salicortin showed high signal abundance under low $\mathrm{N}$ supply, which declined to one fifth after high $\mathrm{N}$ supply (Figure 3c). Also, salicin and tremulacin showed the highest abundances in xylem sap of poplars fed with low $\mathrm{N}$ (Figure 3c).

With the number of 75 identified compounds, a substantial fraction of metabolites represented by the data set was determined, considering the large number of adducts known to be formed by ESI-MS. Our analyses also confirmed metabolites already detected by the targeted approaches (Figure 1 and 2), like organic acids, amino acids but also ABA, pipecolic acid and NHP (Supportive data file S2). Overall, the combined approaches of targeted primary metabolite analysis, phytohormone quantification and non-targeted LC-MS metabolite fingerprinting with subsequent MS/MS based metabolite annotation led to the identification of 122 metabolites and, thus, is the largest xylem sap metabolite database currently available (Supporting Table S3).

\section{Increasing nitrogen concentrations affect the xylem sap proteome diversity}

Proteome analyses showed the highest protein diversity in the xylem sap of high ammoniumand high nitrate-fed plants (Supportive data file S3), indicating that not only the protein concentrations (Table 1) but also the number of proteins increased (Figure 4a). A high number of the xylem sap proteins had a signal peptide, targeting the compound to the extracellular compartment (62.5\%) (Supportive data file S3). Since we did not detect any significant contamination of the xylem sap with the intracellular marker enzyme glucose-6-phophate 
dehydrogenase (cf. Experimental procedures) and since proteins can also be targeted by other mechanisms to the apoplast (Feussner \& Polle, 2015), proteins without known apoplastic target sequence were also considered as likely xylem sap constituents. Rare proteins might have escaped the label-free quantification approach (Cox et al., 2014).

Filtering the proteins that could be quantified in $\geq 10 \%$ of the samples resulted 289 unique proteins, of which 288 were assigned to a poplar gene identifier (Potri ID) and could be mapped to 222 unique Arabidopsis AGIs (Supportive data file S3). The overlap between the ammonium and nitrate treatments was high with 251 shared poplar proteins (Figure 4a).

Under ammonium 32 and under nitrate nutrition five unique proteins were detected (Figure 4a). PCA showed strong overlap of the xylem sap protein profiles obtained under low and intermediate ammonium and nitrate nutrition, whereas xylem sap proteins of high ammonium- and high nitrate-fed plants were clearly separated (Figure 4b).

GO term and KEGG pathway analysis of the xylem sap proteins on the Metascape platform revealed 21 significantly enriched biological functions (Figure 4c). Major functional classes were defense ("Immune response", "Hydrogen peroxide degradation", and "Cellular oxidant detoxification"), cell wall-related processes ("Lignin metabolic process", "Cell wall organization" and "Carbohydrate metabolic processes") and catabolic processes ("Monosaccharide metabolic process", "Pyruvate and aldehyde metabolism", "Aminoglucan metabolism", "Amino sugar and nucleotide sugar metabolism") (Figure 4c). The GO term "Immune response" comprised natriuretic protein, lysine-motif domain GPI-anchored protein 1 (LYM1), peroxidases, chitinases, and bifunctional inhibitor/lipid-transfer protein/seed storage $2 \mathrm{~S}$ albumin superfamily protein. The GO terms "Cell wall metabolism" and "Lignification" included xylanases, glucanases, peroxidases, and laccases and suggested functions such as pectin and hemicellulose metabolism and catalytic activities driving the last step of lignification by $\mathrm{H}_{2} \mathrm{O}_{2}$-dependent peroxidases and $\mathrm{O}_{2}$-dependent laccases (Supportive data file S3). The fewest significant changes in GO terms occurred when the $\mathrm{N}$ supply was increased from low to intermediate ammonium or nitrate levels (Figure 4c).

Using DESeq2 (Love et al., 2014) on protein abundance data (Supportive data file S3), we identified 59 xylem sap proteins that showed significant differences $\left(P_{a d j}<0.05\right)$ in response to changes in $\mathrm{N}$ nutrition. The significant proteins in xylem sap from low and intermediate ammonium fed plants clustered together and were distinct from low and intermediate nitrate- 
fed plants (Figure 5). Proteins in xylem sap from high ammonium- and high nitrate-fed plants formed distinct clusters with the highest number of differentially expressed protein. Under both high ammonium and high nitrate, similar sets of stress-related protein showed higher abundances than under lower $\mathrm{N}$ supply including putative chitinases, peroxidases, laccase, proteases, and peptidases (Figure 5). Overall, our analyses shows that proteins patterns in xylem sap responded strongly to changes in the $\mathrm{N}$ concentrations, especially in the category of phenylpropanoid metabolism. By identification of 289 proteins, we present the largest current xylem sap proteome in a tree species (Supportive data file S3).

\section{High plant nitrogen availability stimulates growth of a poplar xylem endophyte}

To investigate whether the compositional metabolic changes and shifts in the defense proteome affected xylem-colonizing bacteria, we studied growth of $B$. salicis using xylem sap as the growth medium. Bacterial growth was strongest in xylem sap of poplars fed with high ammonium (Figure 6). Xylem sap from plants with intermediate ammonium supply and high nitrate supply afforded similar growth of B. salicis (Figure 6). The lowest growth of $B$. salicis was found in xylem sap of poplars with low nitrate supply (Figure 6). Obviously, B. salicis benefited from an increased nutritional quality of xylem sap from poplars fed with high ammonium.

\section{High and low $\mathbf{N}$ supply elicit stress and immune responses in the leaf transcriptome}

Changes in the $\mathrm{N}$ concentrations in the nutrient solution had drastic effects on the leaf transcriptomes resulting in 9157 differentially expressed genes (DEGs with more than 2-fold changes and $\mathrm{p}_{\mathrm{adj}}<0.05$ ) in response to changes in $\mathrm{N}$ concentrations and $431 \mathrm{DEGs}$ in response to ammonium versus nitrate nutrition (Supportive data file S4). Global nitrogen effects have already been analyzed in several studies (e.g. Robertson \& Vitousek, 2009; Scheible et al., 2004) and therefore, further details are shown in the supplements (Supporting Figure S5). Here, we focused on the question whether our nitrogen treatments elicited distinct immune responses known to occur in response to leaf-feeding insects and methyl jasmonate (MeJA) or in response to biotrophic fungi and SA treatments (Pieterse et al., 2014). 
To test whether changes in $\mathrm{N}$ nutrition resulted in MeJA/herbivory or SA/pathogen-related responses, we applied an in silico strategy: we extracted DEGs $\left(>2\right.$-fold change, $\left.p_{\text {adj }}<0.05\right)$ in response to MeJA, to SA (Luo et al., 2019), to rust fungi (Melampsora medusae, Miranda et al., 2007; Melampsora larici-populina, Rinaldi et al., 2007; Luo et al., 2019), and to herbivory by poplar leaf beetle (Chrysomela populi, Kaling et al., 2018) from previous publications.

We combined the MeJA/Chrysomela (MeJA+Chry) data sets keeping only genes that showed the same direction of change in response to MeJA and in response to Chrysomela (Supportive data file S5). Then, the transcript abundances of the genes in our $\mathrm{N}$ data set that overlapped with the MeJA+Chry matrix were extracted (Supportive data file S5) and clustered in a heatmap (Fig. 7a). DEGs regulated by MeJA and beetle feeding exhibited five main clusters (113 genes) that overlapped with $\mathrm{N}$-responsive genes (Figure 7a). Cluster 1 contained genes with enhanced transcript abundances under low nitrate compared with other $\mathrm{N}$-treatments (Figure 7a). Under MeJA exposure as well as under Chrysomela feeding, the majority of the genes in cluster 1 showed enhanced transcript abundances (see left hand color code in Figure 7a). The genes in cluster 1 were functionally annotated as "JA-mediated signaling pathway", "Response to lipid" and "Wounding" (Figure 7b,c). The genes in cluster 4 and 5 showed highest transcript abundances under high $\mathrm{N}$ supply, especially in response to ammonium (cluster 4), were in most cases positively related to MeJA+Chry induced genes (Figure 7a), and annotated as "Response to wounding", "Response to water deprivation", "Defense response", and "Drug catabolic process" (Figure 7b,c). Cluster 2 and 3 contained genes with decreased transcript abundances under high $\mathrm{N}$ nutrition. The majority of these genes also showed negative responses to MeJA+Chry (Figure 7a). Cluster 2 and 3 were functionally annotated as "Cell wall organization", "Anatomical structure", and "Cellular lipid metabolic process" (Figure 7b,c).

We employed the same strategy to identify leaf rust (Melampsora spp.) and SA co-regulated genes (SA+Mel), their overlap with $\mathrm{N}$-responsive genes, and clustered the resulting set of 219 genes according to $\mathrm{N}$-treatments (Fig. 8a, Supportive data file S5). Cluster 1 contained genes with enhanced transcript abundances under high nitrate that were functionally annotated as "Ethylene activated signaling" (Fig. 8b,c). Cluster 2 contained genes with high transcript abundances for high ammonium and nitrate treatments encompassing the categories "Organic anion transport", "Response to oxidative stress" and "Cell wall biogenesis" (Figure $8 b, c)$. Genes in cluster 4, which showed high transcript abundances under low nitrate treatments, were functionally annotated as "Hormone biosynthetic process" and "Secondary 
metabolism" (Figure 8a-c). Cluster 5 showed high transcript abundances for low nitrate-fed plants (Figure 8a). Cluster 5 was the largest one, with "Defense response to fungus", "Response to bacterium"," Immune system process" and "Regulation of hormone metabolic process" (Figure $8 b, c$ ). In most cases, the genes in cluster 4 and 5 were positively related to $\mathrm{SA}+\mathrm{Mel}$ induced genes (Figure 8a). By our comparison of $\mathrm{N}-$, biotic stress- and phytohormoneresponsive DEGs, we provide a novel resource that can be used in the future to deepen our understanding of the relationship between $\mathrm{N}$ supply and tree stress susceptibility or tolerance.

\section{Discussion}

\section{Xylem saps shows distinct responses to nitrate and ammonium nutrition}

Here, we present the first multi-omics study connecting $\mathrm{N}$ nutrition, xylem sap composition and leaf responses. An important result was that changes in $\mathrm{N}$ nutrition resulted in profound changes in xylem sap composition. These changes affected not only mobile transport forms of $\mathrm{N}$ (nitrate, ammonium, amino acids) and the proteome but all compound classes studied here, including phytohormones, soluble carbohydrates, organic acids, flavonoids, phenolics, benzoates, and many other metabolites. To our very best knowledge the present study reports the largest metabolite library to date available for plant xylem sap and provides in addition to other comprehensive poplar metabolome studies (e.g. Kaling et al., 2018; Tschaplinski et al., 2019) a versatile database for future research.

In agreement with previous studies (Siebrecht and Tischner, 1999), we found that a switch from nitrate to ammonium nutrition caused a switch in the dominance of these compounds in the xylem sap. The nitrate concentrations in the xylem sap (about $3 \mathrm{mM}$ ) found in our study under low nitrate supply were similar to those reported by Siebrecht et al. (2003). In addition to inorganic $\mathrm{N}$, amino acids play a major role as a transport form of $\mathrm{N}$ in the xylem sap (Grassi et al., 2002). In poplars under field and laboratory conditions, glutamine is generally the most abundant xylem sap amino-N form (Dickson et al., 1985; Escher et al., 2004; Siebrecht and Tischner, 1999). In our study, glutamic acid-based amino acids dominated as well, but the fractions of glutamine and glutamate in xylem sap could not be distinguished because of cyclization of glutamate and glutamine to pyroglutamic acid (Purwaha et al., 2014) that happened during derivatization prior to GC-MS analysis applied here (Supporting Figure S2). 
In soil, the concentrations of nitrate and ammonium vary strongly temporally and spatially, for example, due to varying microbial activities and high mobility of nitrate, thus, requiring flexible adjustment of plant uptake (Glass et al., 2002). Here, we show that the form of applied $\mathrm{N}$ resulted in specific effects in some compound classes. For example, high ammonium supply caused a significant increase in xylem sap carbohydrates, whereas the malate concentrations increased under high nitrate. Malate is an important metabolite with major functions during carbohydrate degradation for energy production and via oxaloacetate in anaplerotic reactions. The metabolite ratio of carbohydrates-to-malate regulates photosynthesis by affecting stomatal conductance (Gago et al., 2016; Lima et al., 2019). In line with this notion, we found that the shift in the malate-to-sugar ratio under high nitrate was associated with a much stronger stimulating effect on photosynthesis than high ammonium, although both treatments resulted in similar whole-plant $\mathrm{N}$ concentrations.

Most $\mathrm{N}$-containing compounds found in the xylem sap increased with increasing $\mathrm{N}$ supply, regardless of the $\mathrm{N}$ source but the effects were generally stronger for ammonium than for nitrate nutrition. A novel result was that this behavior was also found for pipecolic acid. Pipecolic acid is not only a degradation product of lysine (Schütte and Seelig, 1967), but its derivate the phytohormone NHP is discussed to be involved in regulating systemic acquired resistance (SAR) (Hartmann et al., 2018; Návarová et al., 2012). Pipecolic acid is intracellularly converted to NHP, which eventually triggers plant immunity responses (Hartmann et al., 2017). Rekhter et al. (2019) showed that conversion of pipecolic acid into NHP is not dependent on SA but establishment of SAR may require positive interplay of NHP and SA (Hartmann and Zeier, 2019). Pipecolic acid and NHP move systemically in plants (Návarová et al., 2012; Y.,-C., Chen et al., 2018; Mohnike et al., 2021) but their presence in xylem sap has not been reported yet. Early findings of Návarová et al. (2012) suggested NHP rather than pipecolic acid, as the bioactive component inducing SAR. In that light and the notion that pipecolate derives from lysine degradation, the increased amounts of pipecolic acid in high $\mathrm{N}$ treated plants may serve as an additional $\mathrm{N}$ transport compound instead of long-distance signaling, a hypothesis that needs to be further elucidated. NHP and SA were low in xylem saps of nitrate-fed plants, regardless of the applied nitrate concentration, whereas NHP increased with increasing ammonium supply. These differences may have implications for SAR. Various studies have shown that SAR signals are influenced by $\mathrm{N}$ nutrition (Sun et al., 
2020). Our study suggests an intricate role of xylem sap for the transmission of these signals. However, this suggestion needs to be tested in further studies.

Secondary or specialized metabolites play eminent roles in trees species for defense and lignin production (Polle et al., 2013). However, little information is available for the regulation of these compounds in apoplastic compartments including xylem sap. Here, we show that all classes of the confirmed specialized metabolites decreased in poplar xylem sap with increasing $\mathrm{N}$ supply, except coumarins. Trade-off between the production of amino- and phenol-based compounds has often been reported and is thought to reflect an ecological plant strategy for carbon utilization balancing growth and defense (Barker et al., 2019). For example, in poplar leaves, specialized metabolites and especially salicinoids are upregulated with decreased $\mathrm{N}$ supply (Bryant et al., 1987; Lindroth and Hwang, 1996). Thereby, the palatability of leaves for a number of herbivores is reduced (Fabisch et al., 2019). However, in xylem sap this clear antagonism in response to changes in $\mathrm{N}$ availability has not been reported before. Our bioassays underpinned that changes of xylem sap composition strongly affected the proliferation of the endophytic bacterium $B$. salicis. The growth conditions were most favorable in xylem sap of high ammonium-fed poplars, which contained the highest ammonium, amino acid and carbohydrate levels, while the abundance of phenol-based compounds was low. Gram-negative bacteria, the category to which B. salicis is belonging to, prefer ammonia over other $\mathrm{N}$-sources (Reitzer, 1996). Erwinia amylovora, a close relative of B. salicis (former E. salicis), shows increased growth rates under high asparagine levels (Lewis and Tolbert, 1964). It is therefore possible that increasing $N$ sources in the xylem sap promoted the bacterial growth in our study. Obviously, defense proteins, which were also enhanced in the xylem sap of high ammonium-fed poplars, could not attenuate growth of $B$. salicis. Our results imply that $B$. salicis is adapted to vascular conditions and provide valuable guidance for future mechanistic analysis of factors that regulate the interaction of vascular endophytes with their host environment.

\section{Nitrogen availability affects signaling and defense compounds in xylem sap}

Many compounds present in the xylem sap have functions in signaling and defenses (Carella et al., 2016; Turnbull and Lopez-Cobollo, 2013). One of the most studied phytohormones in xylem sap is $A B A$. ABA xylem sap concentrations increase under drought (Hansen and Dörffling, 1999; Korovetska et al., 2014; Schachtman and Goodger, 2008). A study with Ricinus 
communis found that the supply with $\mathrm{NH}_{4}{ }^{+}$instead of $\mathrm{NO}_{3}^{-}(1 \mathrm{mM})$ also caused a pronounced increase of ABA in the xylem sap (Peuke et al., 1998). However, in our study application of ammonium instead of nitrate did not affect ABA levels. Since our plants were well irrigated, we did not expect changes in ABA concentrations in the xylem sap.

Here, other phytohormones such as SA, SAG and JA-lle showed strong responses to poplar $\mathrm{N}$ nutrition. These phytohormones have been studied predominantly in xylem sap of crops. For instance, they occur in xylem sap of Brassica napus in the concentration range from 20 to 200 nM (Ratzinger et al., 2009). In poplar xylem sap, we found slightly higher concentrations of these compounds ( 30 to $600 \mathrm{nM}$ ). JA-Ile, SA and its derivative SAG decreased in xylem sap of plants supplied with high N. Both Ja-lle and SA play intricate - but partly divergent - roles in signaling of plant biotic stress (Pieterse et al., 2014, Sun et al., 2020). Here, we found drastic reprogramming of immune responses in leaf transcriptomes that overlapped with biotic stress responses. Our results suggest that xylem sap phytohormones might be involved in mediating these responses but functional analyses are necessary to test this suggestion.

The xylem sap proteome is dominated by proteins required to maintain the integrity of the xylem architecture (cell wall-related enzymes, general metabolism) and a wide array of proteins such as peroxidases, proteases, chitinases, etc., required as first line of stress defense against invading pests (Rodríguez-Celma et al., 2016). The protein concentrations in xylem saps are low, ranging from 5 and $12 \mu \mathrm{g} \mathrm{mL}^{-1}$ across various herbaceous and tree species examined so far (Rodríguez-Celma et al., 2016). These concentrations are in line with our findings in poplar xylem sap, with the exception of high ammonium treated plants, where the protein concentrations amounted more than $20 \mu \mathrm{g} \mathrm{mL}^{-1}$. In xylem saps of different plant species altogether, approximately 350 non-redundant proteins were detected (RodríguezCelma et al., 2016). Previous studies identified 97 proteins in $P$. trichocarpa $\times$. deltoides (Dafoe and Constabel, 2009) and 102 proteins in P. deltoides xylem sap (Pechanova et al., 2010). With the identification of 289 proteins, we report the largest proteome database in poplar xylem sap, so far. Mapping these sequences on Arabidopsis gene loci as done by Rodríguez-Celma et al. (2016), still 222 unique proteins were found. Dafoe and Constable (2009) used a pressure extraction method and reported that $33 \%$ of the identified proteins contain a signal peptide. In our study, in which contamination by intracellular proteins was extremely low, we found that $63 \%$ of the proteins contained a signal peptide. This fraction is similar to those (57\%) reported for $P$. deltoides xylem sap (Pechanova et al., 2010) and for the 
average of xylem sap proteins across different plant species (Rodríguez-Celma et al., 2016). The functional composition found here was also similar to that reported before (Carella et al., 2016; Rodríguez-Celma et al., 2016), supporting species-independent conserved functions of xylem sap proteomes. Our finding that higher $\mathrm{N}$ supply enriched the xylem sap with proteins of similar functional classes additionally points to conserved xylem sap functions. However, under high $\mathrm{N}$ a number of xylem sap proteins showed significant treatment effects, e.g., differential accumulation of peroxidases, chitinases, and dirigent proteins. Proteins in these classes also accumulated in the xylem sap of crop plants upon attack by a vascular pathogen (Floerl et al., 2012; Yang et al., 2020). The N-dependent regulation of the abundances of xylem sap proteins with anti-microbial characteristics and the enhancement of SAR-related phytohormones suggest local (xylem sap) and systemic (leaves) changes of poplar pathogen resistance.

\section{Plant-available nitrogen modules systemic defense responses in leaves}

Our study highlights that xylem sap is not only a transport medium for water and nutrients but a complex matrix containing multiple signaling and defense compounds that show drastic responses to changes in nitrogen nutrition. There is growing awareness that nitrogen, especially nitrate, modulates plant defenses against pathogens (Mur et al., 2017; Sun et al., 2020; Xuan et al., 2017), in addition to its role as a nutrient (Euring et al., 2014; Luo et al., 2015; Wei et al., 2013, Lu et al. 2019, Gan et al. 2016). Here, we demonstrate that low and high $\mathrm{N}$ concentrations systemically regulated poplar leaf defense responses, recruiting JA- and herbivory-related as well as SAR- and pathogen-related pathways. SAR and pathogen-related defenses invoke SA and NHP signaling (Hartmann and Zeier, 2019). These phytohormones increased in xylem sap with increasing nitrogen supply, especially in case of $\mathrm{NH}_{4}^{+}$. If these xylem sap-transported phytohormones were directly invoked in transcriptional defense activation in leaves, we would have expected GO terms such "Immune system response", or "Response to fungus". However, this response was not found under high N, but instead in leaves of plants grown with low nitrate, which contained only moderate SA or NHP levels in the xylem sap. Therefore, direct defense activation by xylem sap SA or NHP is unlikely and the mechanism how xylem sap composition of low nitrate-supplied plants mediates transcriptional activation of defense genes against biotrophic pathogens remained elusive. 
Notably, under low nitrate availability also a significant number of genes associated with the GO term "JA-mediating signaling pathway" were differentially expressed in leaves. These genes were also positively regulated in response to poplar leaf beetle feeding and MeJA exposure (Kaling et al., 2018; Luo et al., 2019) and corresponded here to enhanced levels of JA-lle. The presence of JA-Ile in xylem sap was unexpected because previously only MeJA was identified in xylem sap (tomato, Thorpe et al., 2007). MeJA is a volatile and phloem-mobile long distance signal (Heil and Ton, 2008), while JA-lle is the bio-active compound for intracellular signaling (e.g. Haroth et al., 2019; Thurow et al., 2020). Based on the present observation, it possible that JA-Ile might also serve as a systemic signal in the xylem sap.

In conclusion, we demonstrate the potential of xylem sap to transmit nutritional and hormonal signals that result in differential defense activation depending on the nutritional status. Our study does not suggest trade-off between biotrophic and necrotrophic/herbivore defenses because both strategies were simultaneously transcriptionally activated under low $\mathrm{N}$, especially under low $\mathrm{NO}_{3}{ }^{-}$. It is unknown which changes in xylem sap composition transmitted these responses. However, our encompassing characterization of the xylem sap identified $\mathrm{N}$ driven differences in the abundance of defense proteins, phytohormones, salicinoid-derived compounds as well as many other specialized and primary metabolites, which may be candidates for reprogramming the leaf transcriptome. The results of our study are ecologically highly relevant because they show activation of various defense pathways under resource limitation, pointing to protection of the photosynthetic organs against a broad spectrum of pests. Our study supports that the xylem sap composition contributes to mediate trade-off between defense and growth (Huot et al., 2014) and provides a comprehensive resource for plant researchers.

\section{Experimental procedures}

\section{Plant propagation and nitrogen treatment}

P. $x$ canescens (hybrid of $P$. tremula $\mathrm{x}$ alba, clone INRA 717 1B4, INRA, Nancy, France) plants were propagated and cultivated as described by Müller et al. (2013). Plants were in vitro multiplied by micro-cuttings and grown on solid, half strength Murashige \& Skoog (MS) medium (Murashige \& Skoog, 1962) containing in $1 \mathrm{~L}$ deionized $\mathrm{H}_{2} \mathrm{O} 2.2 \mathrm{~g}$ MS medium (Duchefa Biochemie, Haarlem, Netherlands), $10 \mathrm{~g}$ sucrose (Duchefa), $0.5 \mathrm{~g}$ 2-(N- 
morpholino)ethanesulfonic acid (ULTRON grade, Merck KGaA, Darmstadt, Germany), and $5 \mathrm{~g}$ Gelrite (Duchefa), pH 5.7. The plantlets were kept for four weeks at $23^{\circ} \mathrm{C}$ to $24{ }^{\circ} \mathrm{C}, 60$ to $85 \mu \mathrm{E}$ $\mathrm{m}^{-2} \cdot \mathrm{s}^{-1}$ photosynthetically active radiation (PAR) and a $16 \mathrm{~h} / 8 \mathrm{~h}$ day/night regime. Rooted plantlets were transferred to the greenhouse and further cultivated at $21^{\circ} \mathrm{C}$ under ambient light with additional illumination of $150 \mu \mathrm{E} \mathrm{m}^{-2} \cdot \mathrm{s}^{-1}$ PAR and a $16 / 8 \mathrm{~h}$ day/night cycle. They were potted into $0.65 \mathrm{~L}$ pots (Lamprecht-Verpackungen $\mathrm{GmbH}$, Göttingen, Germany) containing a mixture of washed and twice autoclaved sand ( 0.71 to $1.21 \mathrm{~mm}$ and 0.4 to $0.8 \mathrm{~mm}$ particle size (8:2 v/v), Dorfner $\mathrm{GmbH}$, Hirschau, Germany) and soil (Fruhstorfer Erde "Nullerde", Hawita Gruppe GmbH, Vechta, Germany) at a ratio of 10:2 (v/v). For acclimation to greenhouse conditions, the plants were covered for one week individually with a transparent plastic beaker, which was gradually lifted during the second week and removed after 14 days. During the acclimation phase, all plants were daily irrigated with modified Long Ashton (LA) nutrient solution (Supporting Table S4, after Hewitt, 1952) containing 2 mM KNO as $\mathrm{N}$ source. Excess nutrient solution ran off. The acclimated plants were divided into two groups and watered daily with modified Long Ashton nutrient solution, containing either ammonium ( $2 \mathrm{mM} \mathrm{NH}_{4} \mathrm{Cl}$ ) or nitrate $\left(2 \mathrm{mM} \mathrm{KNO}_{3}\right.$ ) as $\mathrm{N}$ sources (Supporting Table S4). The irrigation volume (per day) was increased with increasing plant height ( $>10 \mathrm{~cm}, 50 \mathrm{~mL} ; 11$ to $30 \mathrm{~cm}, 100 \mathrm{~mL} ; 31-60 \mathrm{~cm}, 150 \mathrm{~mL} ;>61 \mathrm{~cm}, 250 \mathrm{~mL}$ ). After 4 weeks, the plants were transferred into $3 \mathrm{~L}$ pots (Lamprecht-Verpackungen $\mathrm{GmbH}$ ) containing a soil/sand mixture (as above). After eight weeks of ammonium or nitrate pre-treatment, each group was split into three subgroups, which were supplied with either $0.4 \mathrm{mM}(\mathrm{L}), 2.0 \mathrm{mM}(\mathrm{M})$ or $8.0 \mathrm{mM}(\mathrm{H})$ $\mathrm{NH}_{4} \mathrm{Cl}$ or $\mathrm{KNO}_{3}$ for three weeks. Each of the six treatment groups consisted of 10 to 12 individual plants, which were randomized regularly. The experiment was repeated three times but not all measurements were possible in all replications. Therefore, the number of biological replicate per measurement varies as indicated in figure and table legends.

\section{Phenotypic measurements}

The stem was marked $2 \mathrm{~cm}$ above ground. Growth measurements started 14 days after cultivation of the plants in the greenhouse and were conducted regularly once a week. Plant height was measured with a folding ruler and stem diameter was measured with an electronic caliper (Tchibo GmbH, Hamburg, Germany) at the marked position. The final measurements were conducted at the day of harvest. 


\section{Gas exchange measurements}

Gas exchange was measured one day before harvest. A portable photosynthesis system (LI6800, LI-COR Biosciences GmbH, Bad Homburg, Germany) was attached to a fully developed top leaf with a blade length longer than $10 \mathrm{~cm}$, which was not shaded by other leaves. Measurements of net photosynthesis, transpiration, and stomatal conductance were conducted under saturating light conditions (PAR of $800 \mu \mathrm{E} \mathrm{m}^{-2} \mathrm{~s}^{-1}$ ), at ambient $\mathrm{CO}_{2}$ concentrations $\left(387 \pm 17 \mathrm{ppm}\right.$ ) and a mean leaf temperature of $32.6 \pm 4.7^{\circ} \mathrm{C}$. Each leaf was acclimated to the measuring conditions for $60 \mathrm{~s}$ and then measured 3 or 4 times in intervals of $60 \mathrm{~s}$. Mean values of the repeated measurements were calculated and used for further analyses.

\section{Harvest and xylem sap extraction}

After 13 weeks of greenhouse cultivation, the plants ( $n=10$ to 12 per treatment and experiment) were harvested randomly within two days, starting after $3 \mathrm{~h}$ in the light phase. The shoot was cut $5 \mathrm{~cm}$ above the soil surface. The shoot was immediately separated into bark, wood, and leaves. Aliquots of tissues were weighed (lowest $5 \mathrm{~cm}$ of the debarked stem, a fully expanded $8 \mathrm{~cm}$-long leaf), shock-frozen in liquid $\mathrm{N}$ and stored at $-80^{\circ} \mathrm{C}$. Three leaves, one fully expanded from the top, one from the middle section and one from the lower part of the plant were weighed separately, dried and anused for $\mathrm{N}$ analyses. All further leaves and the remaining stem were weighed separately, dried in paper bags for 7 days at $60{ }^{\circ} \mathrm{C}$ and weighed again. Dry biomass of the plant was determined, taking the mass of the samples removed for other analyses into account.

For xylem sap collection, a modified protocol using the natural root pressure was used (Schurr, 1998). Immediately after removing the shoot, a strip of the top $1.5 \mathrm{~cm}$ of bark of the stump was peeled off after cutting through the bark and cambium with a razor blade. The exposed wood was washed with deionized $\mathrm{H}_{2} \mathrm{O}$ and blotted with a paper towel. When the first drops of xylem sap accumulated on the cut wood surface, they were removed by washing with deionized $\mathrm{H}_{2} \mathrm{O}$ and the stump was blotted. Then, a $4 \mathrm{~cm}$ long piece of tight-fitting tube (TYGON ${ }^{\circledR}$-Tubing for Medical Engineering, RCT GmbH \& Co., Heidelberg, Germany) was slipped over the exposed wood and secured at the stump with sticky tape (Durapore ${ }^{\circledR}, 3 \mathrm{M}$ Deutschland $\mathrm{GmbH}$, Neuss, Germany). The sap was pipetted into a $1.5 \mathrm{ml}$ ice cold reaction vessel (Eppendorf AG, Hamburg, Germany) every 10 minutes using a separate glass pipette 
for each plant. The xylem sap was collected for exactly $4 \mathrm{~h}$ and the samples were stored at $80^{\circ} \mathrm{C}$. After xylem sap collection, the roots were washed, weighed, and dried for biomass determination.

\section{Assessment of xylem sap contamination with intracellular compounds}

To test cytosolic contamination, we analyzed glucose-6-phosphate dehydrogenase (EC 1.1.1.49) activities in wood and xylem sap similar as described previously (Polle et al., 1990). Frozen wood was milled (Ball mill MM200, Retsch GmbH, Haan, Germany) whilst cooling with liquid $\mathrm{N}_{2}$. Then, $300 \mathrm{mg}$ of the wood powder or $300 \mu \mathrm{L}$ of the xylem sap were added to $2 \mathrm{~mL}$ of extraction buffer (0.1 M sodium phosphate buffer, containing 0.5\% Triton X-100 (Serva Electrophoresis $\mathrm{GmbH}$, Heidelberg, Germany) and $200 \mathrm{mg}$ insoluble polyvinylpyrrolidone, $\mathrm{pH}$ 7). The extraction buffer was prepared one day before use to enable swelling of the insoluble polyvinylpyrrolidone and kept at $4^{\circ} \mathrm{C}$. Samples were extracted by mixing, incubation for $15 \mathrm{~min}$ on ice and centrifugation at $15000 \times g$ at $4^{\circ} \mathrm{C}$ for $30 \mathrm{~min}$. Then $500 \mu \mathrm{l}$ of the supernatant was filtered through a gel column (NAP 5 Sephadex ${ }^{\circledR}$, Thermo Fisher Scientific Inc., Waltham, Massachusetts, USA), which had been equilibrated and eluted with $1000 \mu \mathrm{L}$ tris(hydroxymethyl)aminomethane (Tris)-buffer (50 mM Tris $\mathrm{HCl}$ (Roth), $1 \mathrm{mM} \mathrm{MgCl}$ (Merck KGaA), pH 8.1). Glucose-6-phosphate activity was determined spectrophotometrically (Bergmeyer, 1974). For this purpose, $500 \mu \mathrm{l}$ Tris-buffer, $300 \mu$ filtered extract, $20 \mu \mathrm{l} 40 \mathrm{mM}$ glucose-6-phosphate (Sigma-Aldrich, now Merck KGaA) and $20 \mu \mathrm{l} 35 \mathrm{mM} \mathrm{NADP}{ }^{+}$(KMF OptiChem, Lohmar, Germany) were added to a cuvette, mixed vigorously and measured at the wavelength of $341 \mathrm{~nm}$ and at room temperature. The production of NADH was recorded for 6 min and the increase in absorbance was used to calculate the enzyme activity with an extinction coefficient of $6.22 \mathrm{mM}^{-1} \mathrm{~cm}^{-1}$.

Glucose-6-phosphate dehydrogenase activities accounted for $0.867 \pm 0.065$ nkat $\mathrm{g}^{-1}$ fresh weight $(n=3)$ in wood and were not detected in xylem sap $\left(-0.002 \pm 0.021 \mathrm{nkat} \mathrm{ml}^{-1}, \mathrm{n}=3\right)$. If we assume that glucose-6-phosphate activity was evenly present in the fluid of fresh wood

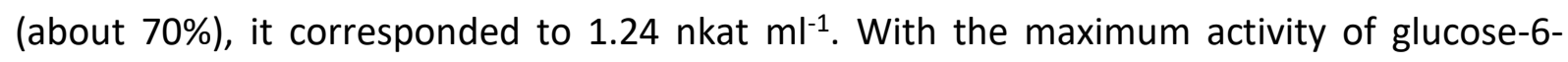
phosphate dehydrogenase in xylem sap of $0.02 \mathrm{nkat} \mathrm{ml}^{-1}$, the potential contamination of xylem sap with cellular compounds from wood was below $1.6 \%$. We further corroborated by proteome analyses that glucose-6-phosphate was not detected in xylem sap (see below). Therefore, cytosolic contamination of the xylem sap was negligible. 


\section{Carbon and nitrogen analyses}

Aliquots of dry leaf, stem, and root tissue were ground to a fine powder in a ball mill (20 s for leaves, 30 s for roots and stems, frequency 30, Type MM400, Retsch, Haan, Germany). Five mg of each sample were weighed into a tin cartouche (IVA Analysentechnik GmbH \& Co.KG., Meerbusch, Germany). Carbon and N concentrations were determined with an element analyzer (Vario Micro Cube ${ }^{\mathrm{TM}}$, Elementar Analysesysteme $\mathrm{GmbH}$, Langensebold, Germany). Acetanilide (Sigma-Aldrich), was used as the standard.

\section{$\mathrm{NH}_{4}{ }^{+}$and $\mathrm{NO}_{3}{ }^{-}$analysis in xylem sap}

Xylem sap ammonium and nitrate concentrations were determined with Spectroquant ${ }^{\circledR}$ kits for ammonium or nitrate (Merck KGaA) spectrophotometric analyses according to the instructions of the manufacturer using $100 \mu \mathrm{l}$ xylem sap. Calibration curves ranging from 0 to $240 \mathrm{nmol} \mathrm{N}$ in $100 \mu \mathrm{l}$ were generated with the Spectroquant kits with $\mathrm{NH}_{4} \mathrm{Cl}$ or $\mathrm{KNO}_{3}$ and used to calculate the concentrations of $\mathrm{NH}_{4}{ }^{+}$and $\mathrm{NO}_{3}{ }^{-}$in xylem sap.

\section{Measurements of xylem sap protein concentrations}

Xylem sap protein concentrations were determined with Pierce ${ }^{\circledR}$ Coomassie Plus kit (Thermo Fisher Scientific), which is based on the Bradford method (Bradford, 1976). Fifty $\mu$ l xylem sap and $50 \mu \mathrm{l}$ Coomassie Plus were mixed in a flat bottom 96 well micro titer plate (Greiner AG, Kremsmünster, Austria) and incubated for $10 \mathrm{~min}$ at room temperature. During incubation, the plates were centrifuged for $5 \mathrm{~min}$ at $4000 \times g$ to remove bubbles. Absorbance was measured at $595 \mathrm{~nm}$ in a plate reader (Infinite M200 Pro ${ }^{\circledR}$, Tecan Group AG, Männedorf, Switzerland). A dilution series ranging from $1.25 \mathrm{\mu g} \mathrm{ml}^{-1}$ to $10 \mu \mathrm{g} \mathrm{ml}^{-1}$ bovine serum albumin (BSA, Merck KGaA) was used for calibration and processed together with the samples.

To test, if the protein assays were disturbed by low molecular weight compounds in the xylem sap, $0.5 \mathrm{ml}$ aliquots of xylem sap were filtered through Sephadex columns (PD SpinTrap ${ }^{\circledR}$ G25, GE Healthcare, Chicago, II, USA) using Tris-buffer (50 mM Tris $\mathrm{HCl}$ (Roth), $1 \mathrm{mM} \mathrm{MgCl}$ (Merck KGaA), pH 8.1) for column equilibration and sample elution. The protein concentrations were measured as above in the filtered extracts. The mean protein concentration differences between filtered and non-filtered xylem sap samples were less than $20 \%$ and not significant. Therefore, we used xylem sap without pretreatment for protein determination. 


\section{Xylem sap metabolites and metabolomics}

\section{Targeted primary metabolite analysis}

Primary metabolites were analyzed by a targeted gas chromatography - mass spectrometry (GC-MS) method. Chemicals and $\mathrm{H}_{2} \mathrm{O}$ used for sample processing were analytical grade (Fisher Scientific). The xylem sap samples were prepared for GC-MS as described by Rotsch et al. (2017). For this purpose, $50 \mu \mathrm{l}$ unprocessed xylem sap were transferred to a $2 \mathrm{~mL}$ reaction tube (Eppendorf) and $200 \mu \mathrm{L}$ extraction medium (methanol : chloroform : $\mathrm{H}_{2} \mathrm{O}, 32.75: 12.5$ :

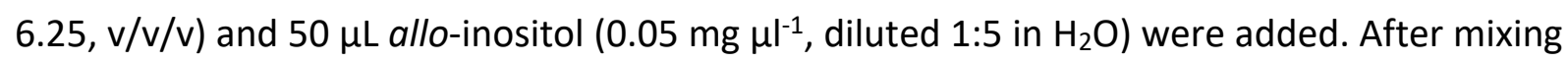
and centrifugation for $2 \mathrm{~min}$ at $20.000 \times g, 80 \mu \mathrm{L}$ of the upper phase were transferred to a new $2 \mathrm{~mL}$ reaction tube (Eppendorf) and evaporated under constant $\mathrm{N}_{2}$ stream. For metabolite derivatization, $15 \mu \mathrm{L}$ MOX (30 mg methoxamine in $1 \mathrm{~mL}$ pyridine) solution was added and the samples were incubated overnight, in the dark and at room temperature. For trimethylsilylation of functional groups, $30 \mu \mathrm{L} \mathrm{N}$-methyl-N-(trimethylsilyl)trifluoroacetamide were added and the sample was incubated for 1-6 h. Sample separation and fragmentation was done according to Hofvander et al. (2016). For this purpose, $1 \mu \mathrm{L}$ of sample was injected into the GC (Sigma-Aldrich 5973 Network mass selective detector attached to an Agilent 6890 gas chromatograph (Agilent Technologies, Santa Clara, CA, USA), equipped with a capillary HP5-MS column (Agilent Technologies, J\&W Scientific, Folsom, CA, USA). Using internal standards, the Golm metabolome database (GMD) (Kopka et al., 2005) and the National Institute of Standards and Technology (NIST) spectral library 2.0f (NIST, 2005, Gaithersburg, $M D, U S A)$, metabolites were identified with the software MSD ChemStation D.01.02.16 (Agilent Technologies). Relative quantification was done by ion count intensity comparison to the internal standard allo-inositol.

\section{Non-targeted metabolite fingerprinting}

The metabolites of the xylem sap were extracted as described by Feussner \& Feussner (2019) in the chapter 'Extraction of metabolites from aqueous solutions of plants and fungal origin'. Non-targeted metabolite fingerprinting was conducted by liquid chromatography coupled to high resolution-mass spectrometry (LC-HRMS) as described in detail by Feussner \& Feussner (2019). Two independent experiments were performed for non-targeted metabolome analysis of xylem sap. One experiment was analyzed by ultra-high-performance LC (UHPLC, LC 1290 Infinity (Agilent Technologies) coupled to a HRMS (6540 UHD Accurate-Mass Q-TOF LC- 
MS instrument (Agilent Technologies). The second experiment was analysed by UPLC (Waters Corporation) coupled to TOF-MS LCT Premier (Waters Corporation). The settings applied for the analyses of the samples were described in detail by Feussner and Feussner (2019). Data acquisition of accurate mass data was performed either with Mass Hunter Acquisition B.03.01 (Agilent Technologies) and analyzed with Mass Hunter Qualitative Analysis (Agilent Technologies) or with MassLynx 4.1 (Waters Corporation). Peak picking and alignment were performed with Profinder B.08.00 (Agilent Technologies) or with MarkerLynx (Waters Corporation) software. The metabolite features covered in both experiments were significantly correlated (Supporting Figure S5). Metabolite annotation was done by database search based on the accurate mass information. The chemical identity of compounds were determined by interpretation of HRMS/MS spectra (Abreu et al., 2020; Green et al., 2020). For further data processing, statistics, visualization as well as for data mining the MarVis-Suite toolbox (http://marvis.gobics.de/, Kaever et al., 2015) was used. The raw data were deposited in the Metabolights database (https://www.ebi.ac.uk/metabolights/) under the accession number MTBLS2305.

\section{Phytohormone analyses in xylem sap}

An LC-MS approach was used for phytohormone analysis, as described by Herrfurth and Feussner (2020) and Mohnike et al. (2021). For phytohormones extraction, $200 \mu \mathrm{L}$ unprocessed xylem sap and $750 \mu \mathrm{L}$ phytohormone solution (10 ng $\mathrm{D}_{4} \mathrm{JA}$-Leu (kindly provided by Otto Miersch, Halle/Saale, Germany), $10 \mathrm{ng} \mathrm{D}_{6}-\mathrm{ABA}, 10 \mathrm{ng} \mathrm{D}_{4}-\mathrm{SA}$ (both from C/D/N Isotopes Inc., Pointe-Claire, Canada), 50 ng D9-Pip (Merck KGaA) and 50 ng ${ }^{13} \mathrm{C}_{6}$-SAG (kindly provided by Prof. Petr Karlovsky, Goettingen, Germany) in $750 \mu \mathrm{L}$ methanol) were mixed. The phytohormones were extracted as described for non-targeted metabolite fingerprinting (as described above). The combined upper phases were evaporated under constant $\mathrm{N}_{2}$ stream and re-suspended in $100 \mu \mathrm{L}$ of acetonitrile : $\mathrm{H}_{2} \mathrm{O}(20: 80, \mathrm{v} / \mathrm{v})$, containing $0.3 \mathrm{mM} \mathrm{NH}_{4} \mathrm{HCOO}$ $(\mathrm{pH} 3.5$, adjusted with formic acid). An ultra-performance liquid chromatography system (ACQUITY UPLCTM system, Waters Corp.) was used for reversed phase separation, followed by nano-electrospray ionization (nanoESI) with a chip ion source (TriVersa Nanomate ; Advion BioSciences, Ithaca, NY, USA). Ionized phytohormones were determined with an AB Sciex 4000 QTRAP $^{\oplus}$ tandem mass spectrometer (AB Sciex, Framingham, MA, USA) in negative and positive 


\section{4}

mode, respectively, using mass transitions and optimized parameters shown in Supporting Table S5. Phytohormone quantification was performed using an internal standard based calibration curve including the data intensity $(\mathrm{m} / \mathrm{z})$ ratios of unlabeled/deuterium-labeled versus molar amounts of unlabeled standards.

\section{Proteomics}

All solvents used for the processing of xylem sap and the resulting proteins were liquid chromatography-mass spectrometry (LC-MS) or high-performance liquid chromatography (HPLC) grade and obtained from Fisher Scientific (Hampton, NH, USA). $400 \mu \mathrm{L}$ xylem sap were lyophilized (Freeze dryer, Piatkowski Forschungsgeräte-Vertrieb, München, Germany) for 5 days. For protein denaturation and to reduce disulfide bonds, the samples were dissolved in $60 \mu \mathrm{L}$ ammonium hydrogen carbonate (ABC, Fluka Analytical, now Sigma-Aldrich and furtheron called Sigma-Aldrich) containing D-1,4-dithiothreitol (DTT, Sigma-Aldrich) (100 mM ABC, $100 \mathrm{mM} \mathrm{DTT}, 1: 4, \mathrm{v} / \mathrm{v}$ ) and $75 \mu \mathrm{L}$ 2,2,2-trifluoroethanol (TFE) and incubated for $30 \mathrm{~min}$ at $60^{\circ} \mathrm{C}$ in a water bath. Samples were centrifuged at $16.000 \times g$ for $10 \mathrm{~min}$ and $100 \mu \mathrm{L}$ supernatant were transferred to a $1.5 \mathrm{~mL}$ low binding micro reaction tube (Eppendorf). For SH-group alkalization, $5 \mu \mathrm{L} 500 \mathrm{mM}$ iodoacetamide (IAA, Sigma-Aldrich) were added and the sample was incubated in darkness for $30 \mathrm{~min}$. Subsequently, $50 \mu \mathrm{L} \mathrm{H}_{2} \mathrm{O}$ were added to dilute the sample. For protein precipitation, $620 \mu \mathrm{L}$ methanol and $200 \mu \mathrm{L}$ chloroform were added and the sample was carefully mixed after each addition (Wessel and Flügge, 1984). Subsequently, $70 \mu \mathrm{L}$ $625 \mathrm{mM} \mathrm{NaCl}$ (Merck KGaA) and $395 \mu \mathrm{L} \mathrm{H}_{2} \mathrm{O}$ were added. The sample was mixed and centrifuged for $20 \mathrm{~min}$ at $16100 \mathrm{xg}$. The proteins accumulated in the interphase. The upper phase was removed by pipetting without disturbing the inter phase. Five hundred $\mu \mathrm{L}$ methanol were added, the sample was mixed and centrifuged for $20 \mathrm{~min}$ at $16.000 \mathrm{xg}$. Thereby, a protein pellet was formed. The supernatant was carefully decanted. The protein pellet was dried at room temperature for about $25 \mathrm{~min}$ and then dissolved in $50 \mu \mathrm{L} 100 \mathrm{mM}$ Tris $\mathrm{HCl}$, pH 8.0 (Roth) by sonication for $3 \mathrm{~s}$. For protein digestion, $1 \mu \mathrm{L}$ trypsin solution (100 ng $\mu \mathrm{L}^{-1}$ Sequencing grade, Roche Deutschland Holding $\mathrm{GmbH}$, Mannheim, Germany) in $10 \mathrm{mM}$ $\mathrm{HCl}$ (Merck KGaA) was added and the sample incubated for $16 \mathrm{~h}$ at $37^{\circ} \mathrm{C}$ in a water bath. Digestion was stopped by addition of $20 \mu \mathrm{L} 20 \mathrm{mM}$ ammonium formate (AF, Sigma-Aldrich). The sample was centrifuged for $20 \mathrm{~min}$ at $16.000 \times g$ and the peptides in the supernatant were purified. 
For peptide purification, Stop and go extraction (STAGE) tips (Rappsilber et al., 2003) were used. A triple layer of the $\mathrm{C} 18$ matrix (C18 Empore ${ }^{\mathrm{TM}}$ Disks, 3M) was inserted into $20 \mu \mathrm{L}$ pipette tips (Gilson Company Inc., Columbus, OH, USA) and this STAGE tip mounted on a $0.5 \mu \mathrm{L}$ micro reaction tube (Eppendorf) in a centrifuge (5415R, Eppendorf). The STAGE tip was loaded with solvents by adding subsequently the following liquids, each followed by centrifugation: $10 \mu \mathrm{L}$ methanol, $1 \mathrm{~min}$ at $1.800 \times \mathrm{g}, 20 \mu \mathrm{L}$ acetonitrile, $1 \mathrm{~min}$ at $1.800 \times \mathrm{g}$, and $20 \mu \mathrm{L} \mathrm{AF}, 4 \mathrm{~min}$ at $1.800 \times \mathrm{g}$. Subsequently, $60 \mu \mathrm{L}$ of peptide solution were added and centrifuged for $10 \mathrm{~min}$ at $1.800 \times \mathrm{g} .15 \mu \mathrm{L} 20 \mathrm{mM} \mathrm{AF}$ were added and centrifuged for $2 \mathrm{~min}$ at $1.800 \times \mathrm{g}$, followed by $2 \mathrm{~min}$ at $2.600 \times \mathrm{g}$. For peptide elution, the STAGE tip was placed in a new, low-bind $0.5 \mu \mathrm{L}$ micro reaction tube (Eppendorf) and $40 \mu \mathrm{L}$ of $60 \%$ acetonitrile in $20 \mathrm{mM} \mathrm{AF}$, pH 10 were added to the tip. The STAGE tip was centrifuged for $4 \mathrm{~min}$ at $1.800 \times \mathrm{g}$, followed by 2 min at $3.000 \mathrm{x}$ g. The eluted peptide solution that had passed through the STAGE tip was evaporated in a vacuum concentrator (Eppendorf). Dried peptides were dissolved in $2 \%$ acetonitrile, $0.1 \%$ formic acid in $\mathrm{H}_{2} \mathrm{O}$ in a volume to obtain a final concentration of $6 \mathrm{ng}$ peptides in $100 \mu \mathrm{L}$ solvent, taking into account a $30 \%$ loss during processing.

Further sample processing was performed in the core facility LCMS Protein Analytics of the University of Goettingen according to the following pipeline used in the study of Horianopoulus et al. (2020): " $2 \mu \mathrm{L}$ of each sample were used for liquid chromatography mass spectrometry (LCMS) analysis. Peptides were loaded on an Acclaim PepMap 100 pre-column (100 $\mu \mathrm{m} \times 2 \mathrm{~cm}, \mathrm{C} 18,3 \mu \mathrm{m}, 100 \AA$; Thermo Fisher Scientific) with $0.07 \%$ trifluoroacetic acid at a flow rate of $20 \mu \mathrm{L} \mathrm{min}^{-1}$ for $3 \mathrm{~min}$. Analytical separation of peptides was performed on an Acclaim PepMap RSLC column (75 $\mu \mathrm{m} \times 50 \mathrm{~cm}, \mathrm{C} 18,3 \mu \mathrm{m}, 100 \AA ̊$; Thermo Fisher Scientific) at a flow rate of $300 \mathrm{~nL} \mathrm{~min}-1$. The solvent composition was gradually changed within $94 \mathrm{~min}$, starting from $96 \%$ solvent $A$ ( $0.1 \%$ formic acid) and $4 \%$ solvent $B(80 \%$ acetonitrile, $0.1 \%$ formic acid) to $10 \%$ solvent B within 2 minutes, to $30 \%$ solvent B within the next $58 \mathrm{~min}$, to $45 \%$ solvent B within the following $22 \mathrm{~min}$, and to $90 \%$ solvent B within the last $12 \mathrm{~min}$ of the gradient. All solvents were Optima grade for LC-MS (Thermo Fisher Scientific). The eluting peptides were on-line ionized by nano-ESI deploying the Nanospray Flex Ion Source (Thermo Scientific) at $1.5 \mathrm{kV}$ (liquid junction) and transferred into a $\mathrm{Q}$ Exactive High Field mass spectrometer (Thermo Fisher Scientific). Full scans in a mass range of 300 to $1650 \mathrm{~m} / \mathrm{z}$ were recorded at a resolution of 30,000, followed by data-dependent top 10 higher-energy collisional dissociation fragmentation at a resolution of 15,000 (dynamic exclusion enabled). 
bioRxiv preprint doi: https://doi org/10.1101/2021.05.28,446139; this version posted May 28,2021 . The copyright holder for this preprint (which was not certified by peer review) is the author/funder, who has granted bioRxiv a license to display the preprint in perpetuity. It is made available under aCC-BY-NC-ND 4.0 International license.

\section{6}

LC-MS method programming and data acquisition were performed with the XCalibur 4.0 software (Thermo Fisher Scientific)."

The resulting raw data were used for protein identification using MaxQuant Software v1.6.6.0 (Cox \& Mann, 2008) with the programs default parameters. Label-free quantification was enabled, trypsin/P was used as digestion mode. For database search and annotation, a JGI/Phytozome12-derived P. trichocarpa (v.3.1) specific database and the Andromeda algorithm (MaxQuant v.1.6.6.0) were used. The results of the MaxQuant database search were evaluated using the Perseus software v.1.6.6.0 (Cox and Mann, 2008). Protein functional group assignment was done with MapMan ( https://mapman.gabipd.org/, assessed 02/2020, Thimm et al., 2004). Metascape (Zhou et al., 2019) was used for functional group enrichment analysis. The raw data were deposited in the PRIDE database (https://www.ebi.ac.uk/pride/) under the accession number PXD024142.

\section{Xylem sap Brennaria salicis growth assay}

A stock culture of Brennaria salicis (formerly Erwinia salicis) strain PD135 (NCCB 87018) was purchased from the Westerdijk Fungal Biodiversity Institute (Wageningen, Netherlands). B. salicis was stored in glycerol stock at $-80^{\circ} \mathrm{C}$ and reactivated on tryptic soy broth (TSB) plates (Art. No. 100550, Merck KGaA). After $24 \mathrm{~h}$ incubation at $22^{\circ} \mathrm{C}$ in the dark, one inoculation loop of bacterial cells was added to $30 \mathrm{~mL}$ liquid TSB. The solution was incubated at $28{ }^{\circ} \mathrm{C}$ and $160^{\circ} \mathrm{rpm}$ for $24^{\circ} \mathrm{h}$ (Maes et al., 2009). Of the bacterial suspension, $1.5 \mathrm{~mL}$ were transferred to a $2 \mathrm{~mL}$ reaction vessel (Sarstedt). The bacteria were spun down at $3930 \times \mathrm{g}$ (Rotanta 96R, Hettich GmbH \& Co. KG, Tuttlingen, Germany) and the supernatant was discarded. Optical density (OD), measured at $600 \mathrm{~nm}$, was adjusted to $O D=1$ by diluting the culture with $1 \mathrm{mM}$ $\mathrm{MgCl}$ (R. L. Smith \& Maguire, 1998). Eight replicates of $100 \mu$ xylem sap of each nitrogen treatment and 8 controls (100 $\mu$ l water) were added to a flat bottom, 96-well plate (Greiner) and $2.5 \mu \mathrm{L}$ bacterial solution was added. The plate was introduced to an automated plate reader (Infinite 200Pro, Tecan) and incubated for $24 \mathrm{~h}$ using a manufactures protocol (Tecan Trading AG, 2012) with following modification: during incubation, the temperature was set to $28^{\circ} \mathrm{C}$ and orbital amplitude to $5 \mathrm{~mm}$. OD was measured at $600 \mathrm{~nm}$ every $30 \mathrm{~min}$.

\section{Leaf transcriptome analysis}

An expanded, fully light exposed top leaf that was formed during the $\mathrm{N}$ treatments was snap frozen in liquid $\mathrm{N}_{2}$ and stored at $-80^{\circ} \mathrm{C}$. Leaves from five ( $8 \mathrm{mM} \mathrm{N}$ treatments) or four plants 
bioRxiv preprint doi: https://doi org/10.1101/2021.05.28,446139; this version posted May 28,2021 . The copyright holder for this preprint (which was not certified by peer review) is the author/funder, who has granted bioRxiv a license to display the preprint in perpetuity. It is made available under aCC-BY-NC-ND 4.0 International license.

of each treatment were used for RNA extraction. Leaves were milled under liquid $\mathrm{N}_{2}$ in a ball mill (MM400, Retsch). The frozen leaf powder of the high $\mathrm{N}$ treatments was extracted with the innuPrep Plant RNA kit (Analytik Jena, Jena, Germany), that of the other treatments using the cetyltrimethyl ammonium bromide method (Chang et al., 1993) with slight modifications reported previously (Janz et al., 2012). RNA concentrations were determined spectophometrically (NanoDrop2000, Thermo Fisher Scientific) and ranged from 92 to $2000 \mathrm{ng}^{\mathrm{L}} \mathrm{L}^{-1}$. We used $10 \mu \mathrm{L}$ of each sample containing at least $1 \mu \mathrm{g}$ RNA for RNA sequencing and library generation and $3 \mu \mathrm{L}$ the determination of RNA integrity numbers (RIN) These analyses were conducted by Chronix Biomedical (Göttingen, Germany), using the RNA Nano Chip Kit (Bioanalyzer 2100, Agilent Technologies) and four samples per treatment with highest RINs were used for further processing (Supporting Table S6). Enrichment of poly-A RNA was performed with the New England Biology (NEB)-Next Poly (A) mRNA Magnetic Isolation Module (New England Biolabs, Ipswich, MA, USA) following the manufacturers' manual. Seventy-five bp single-read sequences were generated using the NextSeq500 (Illumina, Inc., San Diego, C, USA) instrument. The sequences were used to create libraries with NEBNext Ultra RNA Library Prep Kit for Illumina (New England Biolabs).

\section{Bioinformatic analysis of RNAseq data}

Adapter trimming and quality filtering were done with fastP, using default parameters (S., Chen et al., 2018). Criteria for quality filtering included base accuracy, $N$ base number and read length. This procedure resulted in $13 \times 10^{6}$ to $21 \times 10^{6}$ reads per sample (Supporting Table S6). Reads were mapped against the P. tremula $x$ alba 717-1B4 data base (Mader et al., 2016), v. 2, downloaded from http://aspendb.uga.edu) with the read alignment tool Bowtie2 (Langmead and Salzberg, 2012). The relative number of reads successfully mapped to a gene model ranged from $89 \%$ to $94 \%$ (with one outlier, $\mathrm{M} \mathrm{NH}_{4}{ }^{+} 2$ = 77.47\%) (Supporting Table S6). The raw data were deposited in the ArrayExpress database (http://www.ebi.ac.uk/arrayexpress) under the accession number E-MTAB-8930.

Linux command-line utility grep (Torvalds, 2015) was used to extract information from mapping files, which were integrated to count tables with the statistical software $R$ base version (R Studio v. 1.2.5033, R Core Team, 2014). The package DESeq2 (Love et al., 2014) was used to identify differentially expressed genes (DEGs) between the treatments. DEGs per treatment were mapped on KEGG pathways (https://www.genome.jp/kegg/, assessed 
02/2020, Kanehisa \& Goto, 2000). Gene ontology enrichment analyses were executed with Metascape (https://metascape.org, accessed 06/2020, Zhou et al., 2019) using the Arabidopsis best hit AGIs of the poplar DEGs. To identify genes in our data set with roles in poplar fungal, leaf feeding, and phytohormone interactions, DEGs $\left(\log 2>1\right.$, padjusted $\left._{0}<0.05\right)$ published by Kaling et al. (2018), Luo et al. (2019), Miranda et al. (2007) and Rinaldi et al. (2007) were downloaded. The DEGs were filtered and those with consistent up- or downregulation in response to Me-JA (Luo et al. 2019) and leaf beetle treatment (Kaling et al. 2018) were kept and used to extract shared DEGs of the $\mathrm{N}$ treatments. Heatmaps of the shared DEGs were generated with ClustVis (https://biit.cs.ut.ee/clustvis/, Metsalu \& Vilo, 2015). Gene ontology (GO) term enrichment analyses and network analyses of the shared DEGs were conducted with Metascape (https://metascape.org, accessed 06/2020, Zhou et al., 2019) using the Arabidopsis best hit AGIs of the poplar DEGs. The same strategy was used to find shared DEGs between $\mathrm{N}$ treatments and SA and Melampsora exposure using DEGs published by Luo et al. (2019), Miranda et al. (2007) and Rinaldi et al. (2007). The shared DEGS used in our analyses are presented in Supportive data file S5.

\section{Statistical analysis}

Data are shown as box plots or means $( \pm S D)$, if not indicated otherwise. The number of biological replicates is indicated in the tables and figures legends. To compare means, we tested normal distribution of the data sets by visual inspection of residuals or used the Shapiro Wilk test when the visual inspection was unclear (Kim, 2013). If data were not normally distributed, they were log transformed to achieve normal distribution. Statistical tests were conducted with R (R Core Team, 2014), using generalized mixed models, Tukey's test or Welch's t-test in the package Multcomp (Hothorn et al., 2008). Differences between treatments were considered to be significant, when the $p$-values of the post hoc test were $p$ $<0.05$. The packages ggfortify (Tang et al., 2016) and cluster (Maechler, 2019) were used for principal component analyses. Venn diagrams were generated with InteractiVenn (Heberle et al., 2015, http://www.interactivenn.net/).

\section{Acknowledgements}

We gratefully acknowledge the excellent technical assistance of Merle Fastenrath, Cathrin Leibecke, Julian Wellhäuser and Mónica Daniela Rodriguez Nava (Forest Botany and Tree 
Physiology) for supporting plant culture, Sabine Freitag (Service Unit for Metabolomics and Lipidomics) for sample preparation for metabolome analyses and Thomas Klein (Laboratory for Radioisotopes) for RNA extraction. This research was funded by the Deutsche Forschungsgemeinschaft (DFG) (IRTG 2172: PRoTECT, project M2). Proteome analyses was conducted at Service Unit LCMS Protein Analytics of the Göttingen Center for Molecular Biosciences (GZMB) at the Georg-August-University Göttingen (Grant DFG-GZ: INST 186/12301 FUGG to Stefanie Pöggeler).

\section{AUTHOR CONTRIBUTIONS}

KK and AP conceived and planned the study. KK performed the experiments, collected and prepared the samples and contributed to the analyses. INA and KF conducted untargeted metabolome analyses and identified metabolites. $\mathrm{KZ}$ and $\mathrm{CH}$ performed phytohormone analyses. IF supervised the metabolome and phytohormone analyses. TI conducted GCMS analyses of primary metabolites. AM, OV, and KS performed proteome analyses under supervision of GHB. DJ and AP conducted transcriptome analyses. KK synthesized the results, performed statistical analyses and wrote the first draft of the paper. All authors contributed to writing and agreed on the final version of this manuscript.

\section{CONFLICT OF INTEREST}

The authors declare that they have no competing interests

\section{Data availability statement}

Leaf transcriptome: ArrayExpress database, accession number E-MTAB-8930

Xylem sap metabolome: Metabolights database, accession number MTBLS2305

Xylem sap proteome: PRIDE database, accession number PXD024142

\section{Supporting Information}

Additional Supporting Information may be found in the online version of this article.

\begin{tabular}{|l|l|}
\hline File name & Description \\
\hline Supportive tables & Table S1. Plant dry mass, tissue N concentrations and \\
net document, 56 KB & $\begin{array}{l}\text { concentrations of ammonium or nitrate } \\
\text { Table S2. GC-MS detected xylem sap metabolites of } \\
\text { Populus } x \text { canescens, supplied with increasing } \\
\text { concentrations of ammonium or nitrate }\end{array}$ \\
\hline
\end{tabular}




\begin{tabular}{|c|c|}
\hline & $\begin{array}{l}\text { Table S3. Metabolite profile of Populus x canescens } \\
\text { xylem sap, identified by targeted (GC-MS, LC-MS) and } \\
\text { non-targeted approaches (LC Qtof MS) } \\
\text { Table S4. Composition of the nutrient solutions used to } \\
\text { irrigate Populus x canescens during the experiment } \\
\text { Table S5. Mass transitions and optimized parameters } \\
\text { for detection of phytohormones by mass spectrometry } \\
\text { Table S6: Quality and processing details of RNA } \\
\text { sequencing and library generation }\end{array}$ \\
\hline $\begin{array}{l}\text { Supportive figures } \\
\text { Word document, } 380 \mathrm{~KB}\end{array}$ & $\begin{array}{l}\text { Figure S1. Growth and height of poplars supplied with } \\
\text { increasing concentrations of ammonium or nitrate } \\
\text { Figure S2. Spectra obtained by measuring standards of } \\
\text { glutamine and glutamate by GC-MS } \\
\text { Figure S3. Correlation analyses of ion count intensities } \\
\text { of identified metabolites in untargeted approaches of } \\
\text { two independent experiments } \\
\text { Figure S4. Cluster analysis of } 863 \text { features obtained by } \\
\text { untargeted LC Qtof-MS analysis in xylem sap of Populus } \\
\text { x canescens, supplied with increasing concentrations of } \\
\text { ammonium or nitrate } \\
\text { Figure S5. Differentially expressed genes (DEGs) in leaf } \\
\text { transcriptome data of Populus x canescens plants, } \\
\text { supplied with increasing concentrations of ammonium } \\
\text { or nitrate. }\end{array}$ \\
\hline $\begin{array}{l}\text { Supportive data file } \mathbf{S 1} \\
\text { MS Excel, } 963 \mathrm{~KB}\end{array}$ & $\begin{array}{l}\text { Metabolite features in Populus x canescens xylem sap } \\
\text { by LC Qtof MS }\end{array}$ \\
\hline $\begin{array}{l}\text { Supportive data file S2 } \\
\text { MS Excel, } 21 \mathrm{~KB}\end{array}$ & $\begin{array}{l}\text { Detection details of identified Populus x canescens } \\
\text { xylem sap secondary metabolites by LC Qtof MS and } \\
\text { HRMS/MS fragmentation analyses }\end{array}$ \\
\hline $\begin{array}{l}\text { Supportive data file S3 } \\
\text { MS Excel, } 271 \mathrm{~KB}\end{array}$ & Populus $\mathrm{x}$ canescens xylem sap proteome \\
\hline $\begin{array}{l}\text { Supportive data file S4 } \\
\text { MS Excel, } 58 \mathrm{~KB}\end{array}$ & $\begin{array}{l}\text { Differentially expressed genes in leaves of Populus } x \\
\text { canescens treated with same concentration of either } \\
\text { ammonium or nitrate }\end{array}$ \\
\hline $\begin{array}{l}\text { Supportive data file S5 } \\
\text { MS Excel, } 923 \mathrm{~KB}\end{array}$ & $\begin{array}{l}\text { Comparison of 2-fold up or down DEGs in this study } \\
\text { with published studies in response to methyl jasmonate } \\
\text { treatment, salicylic acid, a biotrophic pathogenic } \\
\text { fungus or herbivory }\end{array}$ \\
\hline
\end{tabular}




\section{References:}

Abreu, I. N. et al. (2020) 'A metabolite roadmap of the wood-forming tissue in Populus tremula', New Phytologist, (228), pp. 1559-1572. doi: 10.1111/nph.16799.

Antico, C. J. et al. (2012) 'Insights into the role of jasmonic acid-mediated defenses against necrotrophic and biotrophic fungal pathogens', Frontiers in Biology, 7(1), pp. 48-56. doi: 10.1007/s11515-011-1171-1.

Barker, H. L., Holeski, L. M. and Lindroth, R. L. (2019) 'Independent and interactive effects of plant genotype and environment on plant traits and insect herbivore performance: A metaanalysis with Salicaceae', Functional Ecology, 33(3), pp. 422-435. doi: 10.1111/13652435.13249.

Bergmeyer, H. U. (1974) Methods of Enzymatic Analysis. 2nd edn. Chemie Weinheim.

Bernsdorff, F. et al. (2016) 'Pipecolic acid orchestrates plant systemic acquired resistance and defense priming via salicylic acid-dependent and -independent pathways', The Plant Cell, 28(1), pp. 102-129. doi: 10.1105/tpc.15.00496.

Boeckler, G. A., Gershenzon, J. and Unsicker, S. B. (2011) 'Phenolic glycosides of the Salicaceae and their role as anti-herbivore defenses', Phytochemistry, 72(13), pp. 14971509. doi: 10.1016/j.phytochem.2011.01.038.

Bradford, M. M. (1976) 'A rapid and sensitive method for the quantitation of microgram quantities of protein utilizing the principle of protein-dye binding', Anal Biochem, 72(1-2), pp. 248-254. doi: 10.1016/0003-2697(76)90527-3.

Bryant, J. P. et al. (1987) 'Effect of nitrogen fertilization upon the secondary chemistry and nutritional value of quaking aspen (Populus tremuloides Michx.) leaves for the large aspen tortrix (Choristoneura conflictana (Walker))', Oecologia, 73(4), pp. 513-517. doi: 10.1007/BF00379408.

Carella, P. et al. (2016) 'Vascular sap proteomics: providing insight into long-distance signaling during stress', Frontiers in Plant Science, 7(651). doi: 10.3389/fpls.2016.00651.

Chang, S., Puryear, J. and Cairney, J. (1993) 'A simple and efficient method for isolating RNA from pine trees', Plant Molecular Biology Reporter, 11(2), pp. 113-116. doi: 10.1007/BF02670468.

Chedgy, R. J., Köllner, T. G. and Constabel, C. P. (2015) 'Functional characterization of two acyltransferases from Populus trichocarpa capable of synthesizing benzyl benzoate and salicyl benzoate, potential intermediates in salicinoid phenolic glycoside biosynthesis', Phytochemistry, 113, pp. 149-159. doi: 10.1016/j.phytochem.2014.10.018.

Chen, S. et al. (2018) 'fastp: an ultra-fast all-in-one FASTQ preprocessor', Bioinformatics, 34(17), pp. i884-i890. doi: 10.1093/bioinformatics/bty560.

Chen, Y.-C. et al. (2018) ' $N$-hydroxy-pipecolic acid is a mobile metabolite that induces systemic disease resistance in Arabidopsis', Proceedings of the National Academy of Sciences, 115(21), pp. E4920-E4929. doi: 10.1073/pnas.1805291115. 
bioRxiv preprint doi: https://doi org/10.1101/2021.05.28,446139; this version posted May 28, 2021. The copyright holder for this preprint (which was not certified by peer review) is the author/funder, who has granted bioRxiv a license to display the preprint in perpetuity. It is made available under aCC-BY-NC-ND 4.0 International license.

\section{2}

Cox, J. et al. (2014) 'Accurate proteome-wide label-free quantification by delayed normalization and maximal peptide ratio extraction, termed MaxLFQ', Molecular \& Cellular Proteomics, 13(9), pp. 2513-2526. doi: 10.1074/mcp.M113.031591.

Cox, J. and Mann, M. (2008) 'MaxQuant enables high peptide identification rates, individualized p.p.b.-range mass accuracies and proteome-wide protein quantification', Nature Biotechnology, 26(12), pp. 1367-1372. doi: 10.1038/nbt.1511.

Dafoe, N. J. and Constabel, C. P. (2009) 'Proteomic analysis of hybrid poplar xylem sap', Phytochemistry, 70(7), pp. 856-863. doi: 10.1016/j.phytochem.2009.04.016.

Day, W. R. (1924) 'The watermark disease of the cricket bat Willow (Salix caerulea).', Oxford Forestry Memoirs, (3), p. 30.

Dickson, R. E., Vogelmann, T. C. and Larson, P. R. (1985) 'Glutamine transfer from xylem to phloem and translocation to developing leaves of Populus deltoides', Plant Physiology, 77(2), pp. 412-417. doi: 10.1104/pp.77.2.412.

Escher, P. et al. (2004) 'Spatial and seasonal variation in amino compounds in the xylem sap of a mistletoe (Viscum album) and its hosts (Populus spp. and Abies alba)', Tree Physiology, 24(6), pp. 639-650. doi: 10.1093/treephys/24.6.639.

Euring, D. et al. (2014) 'Nitrogen-driven stem elongation in poplar is linked with wood modification and gene clusters for stress, photosynthesis and cell wall formation', BMC Plant Biology, 14(1), p. 391. doi: 10.1186/s12870-014-0391-3.

Fabisch, T., Gershenzon, J. and Unsicker, S. B. (2019) 'Specificity of herbivore defense responses in a woody plant, black poplar (Populus nigra)', Journal of Chemical Ecology, 45(2), pp. 162-177. doi: 10.1007/s10886-019-01050-y.

Feussner, I. and Polle, A. (2015) 'What the transcriptome does not tell - proteomics and metabolomics are closer to the plants' patho-phenotype', Current Opinion in Plant Biology, 26, pp. 26-31. doi: 10.1016/j.pbi.2015.05.023.

Feussner, K. and Feussner, I. (2019) 'Comprehensive LC-MS-based metabolite fingerprinting approach for plant and fungal-derived samples', in High-Throughput Metabolomics: Methods and Protocols. New York, NY: Springer Science+Business Media, LLC, part of Springer Nature (Methods in Molecular Biology). Available at: https://doi.org/10.1007/978-1-4939-9236-2_11.

Floerl, S. et al. (2012) 'Verticillium longisporum infection affects the leaf apoplastic proteome, metabolome, and cell wall properties in Arabidopsis thaliana', PLoS ONE, 7(2), p. e31435. doi: https://doi.org/10.1371/journal.pone.0031435.

Fujita, Y. et al. (2005) 'AREB1 Is a Transcription Activator of Novel ABRE-Dependent ABA Signaling That Enhances Drought Stress Tolerance in Arabidopsis', The Plant Cell, 17(12), pp. 3470-3488. doi: 10.1105/tpc. 105.035659.

Gago, J. et al. (2016) 'Relationships of leaf net photosynthesis, stomatal conductance, and mesophyll conductance to primary metabolism: a multispecies meta-analysis approach', Plant Physiology, 171(1), pp. 265-279. doi: 10.1104/pp.15.01660.

Gan, H. et al. (2015) 'Phosphorus and nitrogen physiology of two contrasting poplar genotypes when exposed to phosphorus and/or nitrogen starvation', Tree physiology, 36(1), pp. 22-38. 
bioRxiv preprint doi: https://doi org/10.1101/2021.05.28 446139; this version posted May 28, 2021. The copyright holder for this preprint (which was not certified by peer review) is the author/funder, who has granted bioRxiv a license to display the preprint in perpetuity. It is made available under aCC-BY-NC-ND 4.0 International license.

\section{3}

Gessler, A. et al. (1998) 'Soluble N compounds in trees exposed to high loads of N: a comparison between the roots of Norway spruce (Picea abies) and beech (Fagus sylvatica) trees grown under field conditions', New Phytologist, 138(3), pp. 385-399. doi: 10.1046/j.1469-8137.1998.00134.x.

Gessler, A., Kopriva, S. and Rennenberg, H. (2004) 'Regulation of nitrate uptake at the whole-tree level: interaction between nitrogen compounds, cytokinins and carbon metabolism', Tree Physiology, 24(12), pp. 1313-1321. doi: 10.1093/treephys/24.12.1313.

Glass, A. D. M. et al. (2002) 'The regulation of nitrate and ammonium transport systems in plants', Journal of Experimental Botany, 53(370), pp. 855-864. doi: 10.1093/jexbot/53.370.855.

Grassi, G. et al. (2002) 'Measurement of xylem sap amino acid concentrations in conjunction with whole tree transpiration estimates spring $\mathrm{N}$ remobilization by cherry (Prunus avium $\mathrm{L}$.) trees', Plant, Cell \& Environment, 25(12), pp. 1689-1699. doi: 10.1046/j.13653040.2002.00949.x.

Green, K. A. et al. (2020) 'Lolium perenne apoplast metabolomics for identification of novel metabolites produced by the symbiotic fungus Epichloë festucae', New Phytologist, 227(2), pp. 559-571. doi: https://doi.org/10.1111/nph.16528.

Hansen, H. and Dörffling, K. (1999) 'Changes of free and conjugated abscisic acid and phaseic acid in xylem sap of drought-stressed sunflower plants', Journal of Experimental Botany, 50(339), pp. 1599-1605. doi: 10.1093/jxb/50.339.1599.

Harding, S. A. et al. (2009) 'A comparative analysis of phenylpropanoid metabolism, N utilization, and carbon partitioning in fast- and slow-growing Populus hybrid clones', Journal of Experimental Botany, 60(12), pp. 3443-3452. doi: 10.1093/jxb/erp180.

Haroth, S. et al. (2019) 'The glycosyltransferase UGT76E1 significantly contributes to 12-Oglucopyranosyl-jasmonic acid formation in wounded Arabidopsis thaliana leaves', Journal of Biological Chemistry, 294(25), pp. 9858-9872. doi: 10.1074/jbc.RA119.007600.

Hartmann, M. et al. (2017) 'Biochemical principles and functional aspects of pipecolic acid biosynthesis in plant immunity', Plant Physiology, 174(1), pp. 124-153. doi: 10.1104/pp.17.00222.

Hartmann, M. et al. (2018) 'Flavin monooxygenase-generated $N$-hydroxypipecolic acid is a critical element of plant systemic immunity', Cell, 173(2), pp. 456-469.e16. doi: 10.1016/j.cell.2018.02.049.

Hartmann, M. and Zeier, J. (2019) ' $N$-hydroxypipecolic acid and salicylic acid: a metabolic duo for systemic acquired resistance', Current Opinion in Plant Biology, 50, pp. 44-57. doi: 10.1016/j.pbi.2019.02.006.

Heberle, H. et al. (2015) 'InteractiVenn: a web-based tool for the analysis of sets through Venn diagrams', BMC Bioinformatics, 16(1), p. 169. doi: 10.1186/s12859-015-0611-3.

Heil, M. and Ton, J. (2008) 'Long-distance signalling in plant defence', Trends in Plant Science, 13(6), pp. 264-272. doi: 10.1016/j.tplants.2008.03.005.

Herrfurth, C. and Feussner, I. (2020) 'Quantitative jasmonate profiling using a highthroughput UPLC-nanoESI-MS/mMS method', in Champion, A. and Laplaze, L. (eds) Jasmonate in Plant Biology: Methods and Protocols. New York, NY: Springer US (Methods in Molecular Biology), pp. 169-187. doi: 10.1007/978-1-0716-0142-6_13. 
bioRxiv preprint doi: https://doi org/10.1101/2021.05.28,446139; this version posted May 28,2021 . The copyright holder for this preprint (which was not certified by peer review) is the author/funder, who has granted bioRxiv a license to display the preprint in perpetuity. It is made available under aCC-BY-NC-ND 4.0 International license.

\section{4}

Hewitt, E. J. (1952) 'Sand and water culture methods used in the study of plant nutrition', Technical Communication No. 22 of the Commonwealth Bureau of Horticulture and Plantation Crops, (22), p. 241.

Hofvander, P. et al. (2016) 'Potato tuber expression of Arabidopsis WRINKLED1 increase triacylglycerol and membrane lipids while affecting central carbohydrate metabolism', Plant Biotechnology Journal, 14(9), pp. 1883-1898. doi: 10.1111/pbi.12550.

Horianopoulos, L. C. et al. (2020) 'The novel J-domain protein Mrj1 is required for mitochondrial respiration and virulence in Cryptococcus neoformans', mBio, 11(3). doi: 10.1128/mBio.01127-20.

Hothorn, T., Bretz, F. and Westfall, P. (2008) 'Simultaneous inference in general parametric models', Biometrical Journal, 50(3), pp. 346-363. doi: 10.1002/bimj.200810425.

Huot, B. et al. (2014) 'Growth-defense tradeoffs in plants: A balancing act to optimize fitness', Molecular Plant, 7(8), pp. 1267-1287. doi: 10.1093/mp/ssu049.

Huvenne, H., Messens, E. and Maes, M. (2009) 'Willow wood sap promotes the densitydependent pathogenesis of Brenneria salicis', Environmental Microbiology, 11(6), pp. 14631472. doi: 10.1111/j.1462-2920.2009.01874.x.

Jandl, R. et al. (2012) 'Acidification and nitrogen eutrophication of Austrian forest soils', Applied and Environmental Soil Science, (2012), p. e632602. doi: https://doi.org/10.1155/2012/632602.

Janz, D. et al. (2012) 'Salt stress induces the formation of a novel type of "pressure wood" in two Populus species', New Phytologist, 194(1), pp. 129-141. doi:

https://doi.org/10.1111/j.1469-8137.2011.03975.x.

Kaever, A. et al. (2015) 'MarVis-Pathway: integrative and exploratory pathway analysis of non-targeted metabolomics data', Metabolomics, 11(3), pp. 764-777. doi: 10.1007/s11306014-0734-y.

Kaling, M. et al. (2018) 'Mycorrhiza-triggered transcriptomic and metabolomic networks impinge on herbivore fitness', Plant Physiology, 176(4), pp. 2639-2656. doi:

https://doi.org/10.1104/pp.17.01810.

Kanehisa, M. and Goto, S. (2000) 'KEGG: kyoto encyclopedia of genes and genomes', Nucleic Acids Research, 28(1), pp. 27-30. doi: 10.1093/nar/28.1.27.

Kato, T. (1981) 'Major nitrogen compounds transported in xylem vessels from roots to top in Citrus trees', Physiologia Plantarum, 52(2), pp. 275-279. doi: 10.1111/j.1399-

3054.1981.tb08505.x.

Kim, H.-Y. (2013) 'Statistical notes for clinical researchers: assessing normal distribution (2) using skewness and kurtosis', Restorative Dentistry \& Endodontics, 38(1), pp. 52-54. doi: 10.5395/rde.2013.38.1.52.

Kopka, J. et al. (2005) 'GMD@CSB.DB: the Golm metabolome database’, Bioinformatics, 21(8), pp. 1635-1638. doi: 10.1093/bioinformatics/bti236.

Korovetska, H. et al. (2014) 'Signalling mechanisms involved in the response of two varieties of Humulus lupulus L. to soil drying: I. changes in xylem sap pH and the concentrations of abscisic acid and anions', Plant and Soil, 380(1), pp. 375-387. doi: 10.1007/s11104-0142101-1. 
bioRxiv preprint doi: https://doi org/10.1101/2021.05.28.446139; this version posted May 28, 2021. The copyright holder for this preprint (which was not certified by peer review) is the author/funder, who has granted bioRxiv a license to display the preprint in perpetuity. It is made available under aCC-BY-NC-ND 4.0 International license.

Langmead, B. and Salzberg, S. L. (2012) 'Fast gapped-read alignment with Bowtie 2', Nature Methods, 9(4), pp. 357-359. doi: 10.1038/nmeth.1923.

Lewis, L. N. and Tolbert, N. E. (1964) 'Nitrogen requirement and metabolism of Erwinia amylovora', Physiologia Plantarum, 17(1), pp. 44-55.

Lima, V. F. et al. (2019) 'The sucrose-to-malate ratio correlates with the faster CO2 and light stomatal responses of angiosperms compared to ferns', New Phytologist, 223(4), pp. 18731887. doi: 10.1111/nph.15927.

Lindroth, R. L. and Hwang, S.-Y. (1996) 'Clonal variation in foliar chemistry of quaking aspen (Populus tremuloides Michx.)', Biochemical Systematics and Ecology, 24(5), pp. 357-364. doi: 10.1016/0305-1978(96)00043-9.

Love, M., Huber, W. and Anders, S. (2014) 'Moderated estimation of fold change and dispersion for RNA-seq data with DESeq2', Genome Biology, 15(12), pp. 1-21. doi: 10.1186/s13059-014-0550-8.

Luo, J. et al. (2015) 'Global poplar root and leaf transcriptomes reveal links between growth and stress responses under nitrogen starvation and excess', Tree Physiology, 35(12), pp. 1283-1302. doi: 10.1093/treephys/tpv091.

Luo, J. et al. (2019) 'Integrated transcriptome analysis reveals plant hormones jasmonic acid and salicylic acid coordinate growth and defense responses upon fungal infection in poplar', Biomolecules, 9(1), p. 12. doi: 10.3390/biom9010012.

Mader, M. et al. (2016) 'Whole-genome draft assembly of Populus tremula x P. alba clone INRA 717-1B4', Silvae genetica : Zeitschrift für Forstgenetik und Forstpflanzenzüchtung, 65(2), pp. 74-79. doi: 10.1515/sg-2016-0019.

Madritch, M. D. and Lindroth, R. L. (2015) 'Condensed tannins increase nitrogen recovery by trees following insect defoliation', New Phytologist, 208(2), pp. 410-420. doi:

10.1111/nph.13444.

Maechler, M. (2019) '"Finding groups in data": Cluster analysis extended Rousseeuw et.', $R$ Packag. version 2.0, 6.

Maes, M., Huvenne, H. and Messens, E. (2009) 'Brenneria salicis, the bacterium causing watermark disease in willow, resides as an endophyte in wood', Environmental Microbiology, 11(6), pp. 1453-1462. doi: 10.1111/j.1462-2920.2009.01873.x.

Manninen, A.-M., Holopainen, T. and Holopainen, J. K. (1998) 'Susceptibility of ectomycorrhizal and non-mycorrhizal Scots pine (Pinus sylvestris) seedlings to a generalist insect herbivore, Lygus rugulipennis, at two nitrogen availability levels', The New Phytologist, 140(1), pp. 55-63. doi: 10.1046/j.1469-8137.1998.00246.x.

Marschner, H. (2011) Marschner's mineral nutrition of higher plants. Academic press.

Menz, J. et al. (2016) 'Early nitrogen-deprivation responses in Arabidopsis roots reveal distinct differences on transcriptome and (phospho-) proteome levels between nitrate and ammonium nutrition', The Plant Journal, 88(5), pp. 717-734. doi: 10.1111/tpj.13272.

Merbach, W. et al. (1996) 'Nitrous oxide and methane emissions from riparian areas of ponded depressions of northeast Germany', Journal of Applied Botany, 70, pp. 134-136. 
bioRxiv preprint doi: https://doi org/10.1101/2021.05.28 446139; this version posted May 28, 2021. The copyright holder for this preprint (which was not certified by peer review) is the author/funder, who has granted bioRxiv a license to display the preprint in perpetuity. It is made available under aCC-BY-NC-ND 4.0 International license.

\section{6}

Metsalu, T. and Vilo, J. (2015) 'ClustVis: a web tool for visualizing clustering of multivariate data using Principal Component Analysis and heatmap', Nucleic Acids Research, 43(W1), pp. W566-W570. doi: 10.1093/nar/gkv468.

Miranda, M. et al. (2007) 'The transcriptional response of hybrid poplar (Populus trichocarpa $\mathrm{x} P$. deltoids) to infection by Melampsora medusae leaf rust involves induction of flavonoid pathway genes leading to the accumulation of proanthocyanidins', Molecular Plant-Microbe Interactions, 20(7), pp. 816-831. doi: 10.1094/MPMI-20-7-0816.

Mohnike, L. et al. (2021) 'The glycosyltransferase UGT76B1 modulates $N$-hydroxy-pipecolic acid homeostasis and plant immunity', The Plant Cell, (koaa045). doi:

$10.1093 /$ plcell/koaa045.

Morseletto, P. (2019) 'Confronting the nitrogen challenge: Options for governance and target setting', Global Environmental Change, 54, pp. 40-49. doi:

10.1016/j.gloenvcha.2018.10.010.

Mur, L. A. J. et al. (2017) 'Moving nitrogen to the centre of plant defence against pathogens', Annals of Botany, 119(5), pp. 703-709. doi: 10.1093/aob/mcw179.

Murashige, T. and Skoog, F. (1962) 'A revised medium for rapid growth and bio assays with tobacco tissue cultures', Physiologia Plantarum, 15(3), pp. 473-497. doi: 10.1111/j.13993054.1962.tb08052.x.

Návarová, H. et al. (2012) 'Pipecolic acid, an endogenous mediator of defense amplification and priming, is a critical regulator of inducible plant immunity', The Plant Cell, 24(12), pp. 5123-5141. doi: 10.1105/tpc.112.103564.

Nerg, A.-M. et al. (2008) 'The significance of ectomycorrhizas in chemical quality of silver birch foliage and above-ground insect herbivore performance', Journal of Chemical Ecology, 34(10), pp. 1322-1330. doi: 10.1007/s10886-008-9542-z.

Nie, X. et al. (2017) 'Soil nitrogen storage, distribution, and associated controlling factors in the Northeast Tibetan plateau shrublands', Forests, 8(11), p. 416. doi:

https://doi.org/10.3390/f8110416.

Pechanova, O. et al. (2010) 'Apoplast proteome reveals that extracellular matrix contributes to multistress response in poplar', BMC Genomics, 11(1), p. 674. doi: 10.1186/1471-216411-674.

Peuke, A. D., Jeschke, W. D. and Hartung, W. (1998) 'Foliar application of nitrate or ammonium as sole nitrogen supply in Ricinus communis. II. The flows of cations, chloride and abscisic acid', The New Phytologist, 140(4), pp. 625-636. doi: 10.1046/j.14698137.1998.00304.x.

Pieterse, C. M. J. et al. (2014) 'Induced systemic resistance by beneficial microbes', Annual Review of Phytopathology, 52(1), pp. 347-375. doi: 10.1146/annurev-phyto-082712-102340.

Polle, A. et al. (1990) 'Composition and properties of hydrogen peroxide decomposing systems in extracellular and total extracts from needles of norway spruce (Picea abies L., Karst.)', Plant Physiology, 94(1), pp. 312-319. doi: 10.1104/pp.94.1.312.

Polle, A. et al. (2013) 'Poplar genetic engineering: promoting desirable wood characteristics and pest resistance', Applied Microbiology and Biotechnology, 97(13), pp. 5669-5679. doi: 10.1007/s00253-013-4940-8. 
bioRxiv preprint doi: https://doi org/10.1101/2021.05.28.446139; this version posted May 28, 2021. The copyright holder for this preprint (which was not certified by peer review) is the author/funder, who has granted bioRxiv a license to display the preprint in perpetuity. It is made available under aCC-BY-NC-ND 4.0 International license.

Purwaha, P. et al. (2014) 'An artifact in LC-MS/MS measurement of glutamine and glutamic acid: In-source cyclization to pyroglutamic acid', Analytical Chemistry, 86(12), pp. 56335637. doi: 10.1021/ac501451v.

R Core Team (2014) 'R: A language and environment for statistical computing'. $R$ Foundation for Statistical Computing, Vienna, Austria. Available at: http://www.R-project.org/.

Rappsilber, J., Ishihama, Y. and Mann, M. (2003) 'Stop and go extraction tips for matrixassisted laser desorption/ionization, nanoelectrospray, and LC/MS sample pretreatment in proteomics', Analytical Chemistry, 75(3), pp. 663-670. doi: 10.1021/ac026117i.

Ratzinger, A. et al. (2009) 'Salicylic acid and salicylic acid glucoside in xylem sap of Brassica napus infected with Verticillium longisporum', Journal of Plant Research, 122(5), pp. 571579. doi: 10.1007/s10265-009-0237-5.

Reichardt, P. B. et al. (1991) 'Carbon/nutrient balance as a predictor of plant defense in Alaskan balsam poplar: Potential importance of metabolite turnover', Oecologia, 88(3), pp. 401-406. doi: 10.1007/BF00317585.

Reitzer, L. J. (1996) 'Sources of nitrogen and their utilization', Escherichia coli and Salmonella: cellular and molecular biology, 2nd ed. ASM Press, Washington, DC, pp. 380390.

Rekhter, D. et al. (2019) 'Isochorismate-derived biosynthesis of the plant stress hormone salicylic acid', Science, 365(6452), pp. 498-502. doi: 10.1126/science.aaw1720.

Rennenberg et al. (2009) 'Nitrogen balance in forest soils: nutritional limitation of plants under climate change stresses', Plant Biology, 11, pp. 4-23. doi: 10.1111/j.1438-

8677.2009.00241.x.

Rennenberg, H. and Dannenmann, M. (2015) 'Nitrogen nutrition of trees in temperate forests-the significance of nitrogen availability in the pedosphere and atmosphere', Forests, 6(8), pp. 2820-2835. doi: 10.3390/f6082820.

Rinaldi, C. et al. (2007) 'Transcript profiling of poplar leaves upon infection with compatible and incompatible strains of the foliar rust Melampsora larici-populina', Plant Physiology, 144(1), pp. 347-366. doi: 10.1104/pp.106.094987.

Robertson, G. P. and Vitousek, P. M. (2009) 'Nitrogen in agriculture: Balancing the cost of an essential resource', Annual Review of Environment and Resources, 34(1), pp. 97-125. doi: 10.1146/annurev.environ.032108.105046.

Rodríguez-Celma, J. et al. (2016) 'Plant fluid proteomics: Delving into the xylem sap, phloem sap and apoplastic fluid proteomes', Biochimica et Biophysica Acta (BBA) - Proteins and Proteomics, 1864(8), pp. 991-1002. doi: 10.1016/j.bbapap.2016.03.014.

Rotsch, A. H. et al. (2017) 'Central metabolite and sterol profiling divides tobacco male gametophyte development and pollen tube growth into eight metabolic phases', The Plant Journal, 92(1), pp. 129-146. doi: 10.1111/tpj.13633.

Rubert-Nason, K. F. et al. (2015) 'Influence of genotype, environment, and gypsy moth herbivory on local and systemic chemical defenses in trembling aspen (Populus tremuloides)', Journal of Chemical Ecology, 41(7), pp. 651-661. doi: 10.1007/s10886-0150600-z.

Schachtman, D. P. and Goodger, J. Q. D. (2008) 'Chemical root to shoot signaling under drought', Trends in Plant Science, 13(6), pp. 281-287. doi: 10.1016/j.tplants.2008.04.003. 
Scheible, W.-R. et al. (2004) 'Genome-wide reprogramming of primary and secondary metabolism, protein synthesis, cellular growth processes, and the regulatory infrastructure of Arabidopsis in response to nitrogen', Plant Physiology, 136(1), pp. 2483-2499. doi: 10.1104/pp.104.047019.

Schimel, J. P. and Bennett, J. (2004) 'Nitrogen Mineralization: Challenges of a Changing Paradigm', Ecology, 85(3), pp. 591-602. doi: 10.1890/03-8002.

Schuman, M. C. et al. (2018) 'The active jasmonate JA-lle regulates a specific subset of plant jasmonate-mediated resistance to herbivores in nature', Frontiers in Plant Science, 9. doi: $10.3389 /$ fpls.2018.00787.

Schurr, U. (1998) 'Xylem sap sampling—new approaches to an old topic', Trends in Plant Science, 3(8), pp. 293-298. doi: 10.1016/S1360-1385(98)01275-8.

Schütte, H. R. and Seelig, G. (1967) 'Zur Biosynthese der Pipecolinsäure in Phaseolus vulgaris', Zeitschrift für Naturforschung B, 22(8), pp. 824-826. doi: 10.1515/znb-1967-0806.

Siebrecht et al. (2003) 'Nutrient translocation in the xylem of poplar - diurnal variations and spatial distribution along the shoot axis', Planta, 217(5), pp. 783-793. doi: 10.1007/s00425003-1041-4.

Siebrecht, S. and Tischner, R. (1999) 'Changes in the xylem exudate composition of poplar (Populus tremula $\times$ P. alba) - dependent on the nitrogen and potassium supply', Journal of Experimental Botany, 50, pp. 1797-1806. doi: 10.1093/jexbot/50.341.1797.

Stevens, C. J. (2019) 'Nitrogen in the environment', Science, 363(6427), pp. 578-580. doi: 10.1126/science.aav8215.

Sun, Y. et al. (2020) 'Unravelling the roles of nitrogen nutrition in plant disease defences', International Journal of Molecular Sciences, 21(2), p. 572. doi: 10.3390/ijms21020572.

Tang, Y., Horikoshi, M. and Li, W. (2016) 'ggfortify: unified interface to visualize statistical results of popular R packages', The $R$ Journal, 8(2), p. 474. doi: 10.32614/RJ-2016-060.

Thimm, O. et al. (2004) 'MAPMAN: a user-driven tool to display genomics data sets onto diagrams of metabolic pathways and other biological processes', The Plant Journal: For Cell and Molecular Biology, 37(6), pp. 914-939. doi: 10.1111/j.1365-313x.2004.02016.x.

Thorpe, M. R. et al. (2007) '11C-imaging: methyl jasmonate moves in both phloem and xylem, promotes transport of jasmonate, and of photoassimilate even after proton transport is decoupled', Planta, 226(2), pp. 541-551. doi: 10.1007/s00425-007-0503-5.

Thurow, C. et al. (2020) 'Induction of jasmonoyl-isoleucine (JA-lle)-dependent JASMONATE ZIM-DOMAIN(JAZ) genes in NaCl-treated Arabidopsis thaliana roots can occur at very low JA-lle levels and in the absence of the JA/JA-lle transporter JAT1/AtABCG16', Plants (Basel, Switzerland), 9(12), p. 1635. doi: 10.3390/plants9121635.

Torvalds, L. (2015) Linux kernel source, 2008-02-21. http://www. kernel. org.

Tromp, J. and Ovaa, J. C. (1976) 'Effect of time of nitrogen application on amino-nitrogen composition of roots and xylem sap of apple', Physiologia Plantarum, 37(1), pp. 29-34. doi: 10.1111/j.1399-3054.1976.tb01868.x.

Tschaplinski, T. J. et al. (2019) 'The nature of the progression of drought stress drives differential metabolomic responses in Populus deltoides', Annals of Botany, 124(4), pp. 617626. doi: $10.1093 / \mathrm{aob} / \mathrm{mcz} 002$. 
bioRxiv preprint doi: https://doi org/10.1101/2021.05.28 446139; this version posted May 28,2021 . The copyright holder for this preprint (which was not certified by peer review) is the author/funder, who has granted bioRxiv a license to display the preprint in perpetuity. It is made available under aCC-BY-NC-ND 4.0 International license.

\section{9}

Turnbull, C. G. N. and Lopez-Cobollo, R. M. (2013) 'Heavy traffic in the fast lane: longdistance signalling by macromolecules', New Phytologist, 198(1), pp. 33-51. doi: 10.1111/nph.12167.

Vlot, A. C., Dempsey, D. A. and Klessig, D. F. (2009) 'Salicylic acid, a multifaceted hormone to combat disease', Annual Review of Phytopathology, 47(1), pp. 177-206. doi: 10.1146/annurev.phyto.050908.135202.

Weber, P. et al. (1998) 'Metabolic responses of Norway spruce (Picea abies) trees to longterm forest management practices and acute (NH4)2SO4 fertilization: transport of soluble non-protein nitrogen compounds in xylem and phloem', New Phytologist, 140(3), pp. 461475. doi: 10.1111/j.1469-8137.1998.00285.x.

Wei, H. et al. (2013) 'Nitrogen deprivation promotes Populus root growth through global transcriptome reprogramming and activation of hierarchical genetic networks', New Phytologist, 200(2), pp. 483-497. doi: 10.1111/nph.12375.

Wessel, D. and Flügge, U. I. (1984) 'A method for the quantitative recovery of protein in dilute solution in the presence of detergents and lipids', Analytical Biochemistry, 138(1), pp. 141-143. doi: 10.1016/0003-2697(84)90782-6.

Xuan, W., Beeckman, T. and Xu, G. (2017) 'Plant nitrogen nutrition: sensing and signaling', Current Opinion in Plant Biology, 39, pp. 57-65. doi: 10.1016/j.pbi.2017.05.010.

Yang, J. et al. (2020) 'Proteomic analyses on xylem sap provides insights into the defense response of Gossypium hirsutum against Verticillium dahliae', Journal of Proteomics, 213, p. 103599. doi: 10.1016/j.jprot.2019.103599.

Yu, D. et al. (2019) 'Abscisic acid signalling mediates biomass trade-off and allocation in poplar', New Phytologist, p. nph.15878. doi: 10.1111/nph.15878.

Zhou, Y. et al. (2019) 'Metascape provides a biologist-oriented resource for the analysis of systems-level datasets', Nature Communications, 10(1), p. 1523. doi: 10.1038/s41467-01909234-6. 
bioRxiv preprint doi: https://doi.org/10.1101/2021.05.28.446139; this version posted May 28, 2021. The copyright holder for this preprint (which was not certified by peer review) is the author/funder, who has granted bioRxiv a license to display the preprint in perpetuity. It is made available under aCC-BY-NC-ND 4.0 International license.

40

Table 1: Xylem sap $\mathrm{NH}_{4}-\mathrm{N}, \mathrm{NO}_{3}-\mathrm{N}$, and protein concentrations in Populus $x$ canescens treated with different forms and concentrations of nitrogen

\begin{tabular}{lccr}
\hline Treatment & $\begin{array}{c}\text { Xylem sap } \mathrm{NH}_{4}-\mathbf{N} \\
(\mathbf{m M})\end{array}$ & $\begin{array}{c}\text { Xylem sap NO}{ }_{3}-\mathbf{N} \\
(\mathbf{m M})\end{array}$ & $\begin{array}{c}\text { Xylem sap protein } \\
\left(\boldsymbol{\mu g} \mathbf{~ m L}^{-1}\right)\end{array}$ \\
\hline $\mathrm{NH}_{4}{ }^{+} \mathrm{L}$ & $8.5 \pm 4.8 \mathrm{a}$ & $2.7 \pm 1.0 \mathrm{a}$ & $3.7 \pm 1.4 \mathrm{a}$ \\
$\mathrm{NH}_{4}{ }^{+} \mathrm{M}$ & $33.5 \pm 10.7 \mathrm{a}$ & $1.6 \pm 0.2 \mathrm{a}$ & $5.7 \pm 1.8 \mathrm{a}$ \\
$\mathrm{NH}_{4}{ }^{+} \mathrm{H}$ & $210.8 \pm 33.2 \mathrm{~b} \dagger$ & $1.2 \pm 0.2 \mathrm{a}$ & $23.7 \pm 2.5 \mathrm{c}$ \\
$\mathrm{NO}_{3}{ }^{-} \mathrm{L}$ & $7.1 \pm 2.9 \mathrm{a}$ & $3.3 \pm 1.0 \mathrm{a}$ & $5 \pm 0.5 \mathrm{a}$ \\
$\mathrm{NO}_{3}{ }^{-} \mathrm{M}$ & $26.3 \pm 7.0 \mathrm{a}$ & $81.2 \pm 92.0 \mathrm{a}$ & $5 \pm 1.0 \mathrm{a}$ \\
$\mathrm{NO}_{3}{ }^{-} \mathrm{H}$ & $29 \pm 18.4 \mathrm{a}$ & $386.4 \pm 268.5 \mathrm{~b} \dagger$ & $9.8 \pm 2.8 \mathrm{~b}$ \\
\hline
\end{tabular}

$\mathrm{L}=0.4 \mathrm{mM}, \mathrm{M}=2.0 \mathrm{mM}, \mathrm{H}=8.0 \mathrm{mM}$ nitrogen supplied in nutrient solution. Data show means $(n=5 \pm S D)$, unless indicated by a $\dagger$. Those data are means of $n=10( \pm S D)$.

Different letters in a column indicate significant differences at $p \leq 0.05$ according to Tukey's-Kramer post-hoc test. 
bioRxiv preprint doi: https://doi org/10.1101/2021.05.28.446139; this version posted May 28, 2021. The copyright holder for this preprint (which was not certified by peer review) is the author/funder, who has granted bioRxiv a license to display the preprint in perpetuity. It is made available under aCC-BY-NC-ND 4.0 International license.

a

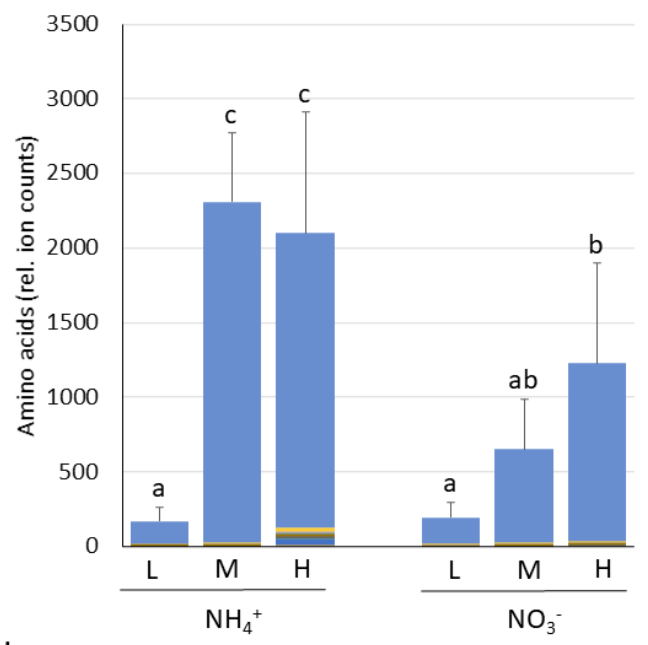

b

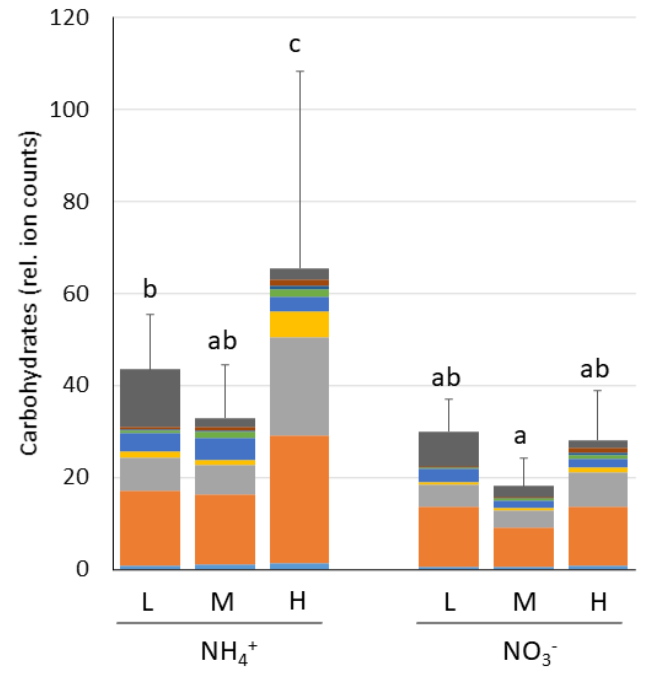

C

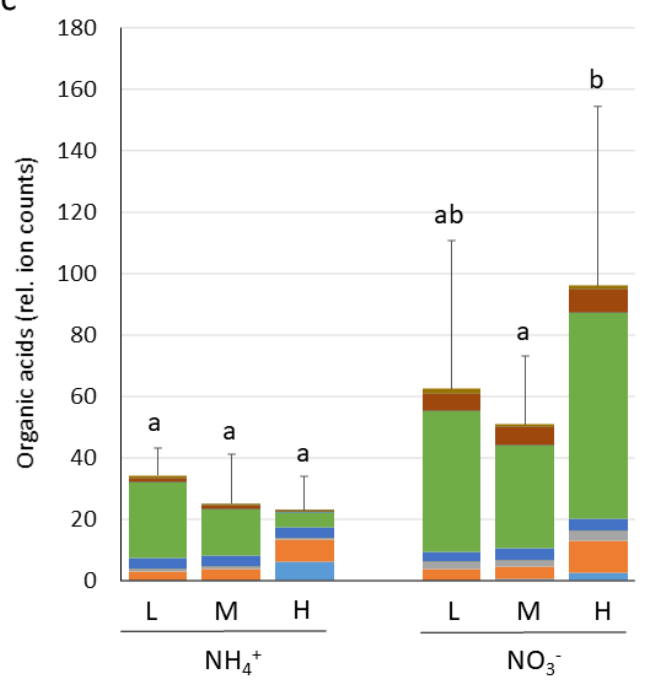

\author{
- Pyro-Glu, Glu, Gln \\ = Valine \\ $\square$ Tyrosine \\ - Threonine \\ - Serine \\ - Proline \\ - Lysine \\ - Leucine \\ - Isoleucine \\ - Glycine \\ - 4-Aminobutyrate \\ - Aspartate \\ - Asparagine \\ - 3 -cyano-Alanine \\ - Alanine \\ - 2-Aminobutyrate \\ - $\beta$-Alanine
}

- Sucrose

- Pentose 3

- Pentose 2

- Pentose 1

- Hexoketose

- Hexoaldose

alucose

- Fructose

Desoxyhexose

Figure 1: Relative abundances of a) amino acids, b) soluble carbohydrates and c) organic acids in Populus $\mathrm{x}$ canescens xylem sap. Xylem saps were collected three weeks after feeding poplars with $\mathrm{L}$ (0.4 mM), M (2.0 mM) or H (8.0 mM) ammonium or nitrate in the nutrient solution. Pyr-Glu, Glu, Gln indicates the sum of pyroglutamate, glutamate and glutamine. Supportive Figure S2 provides further information. Stacked bars show means of the relative abundances for the indicated compounds. Error bars refer to the variation of the sum of compounds. Different letters above the bars indicate significant differences at $\mathrm{p} \leq 0.05$ according to Tukey's post-hoc test, $\mathrm{n}=8$ per treatment. 
a

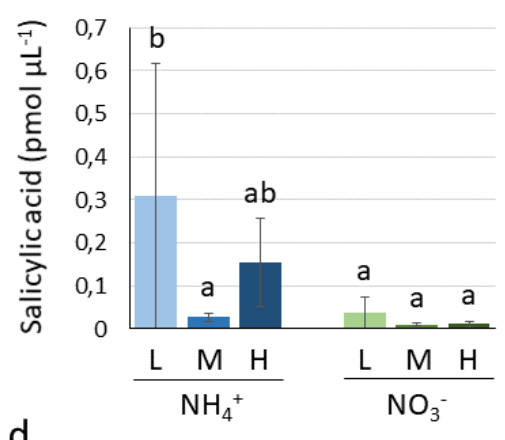

d

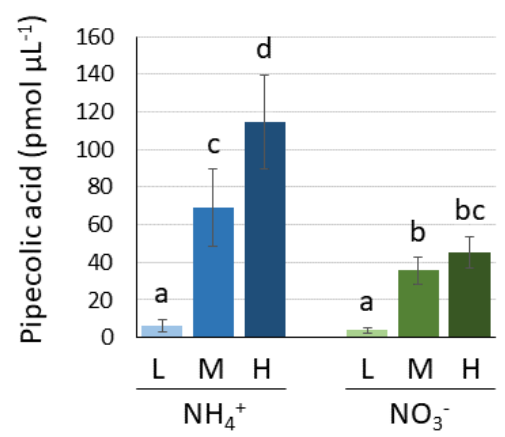

b
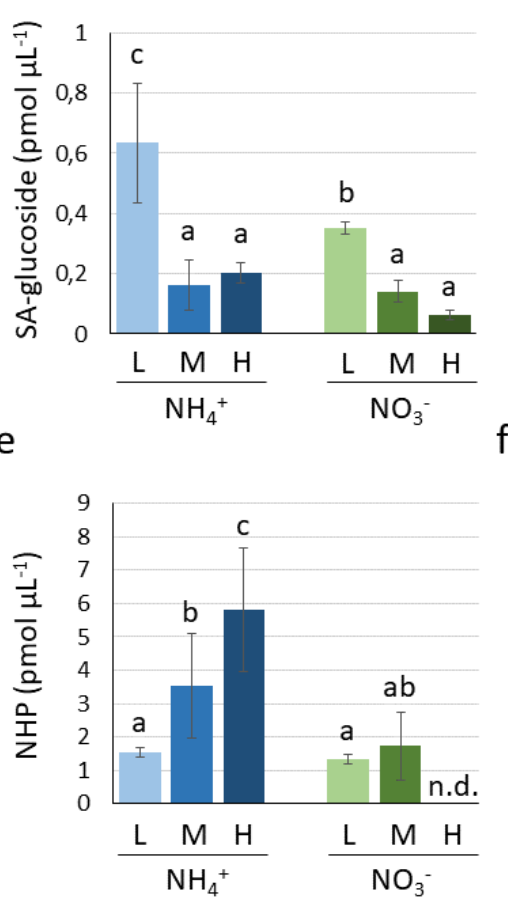

C
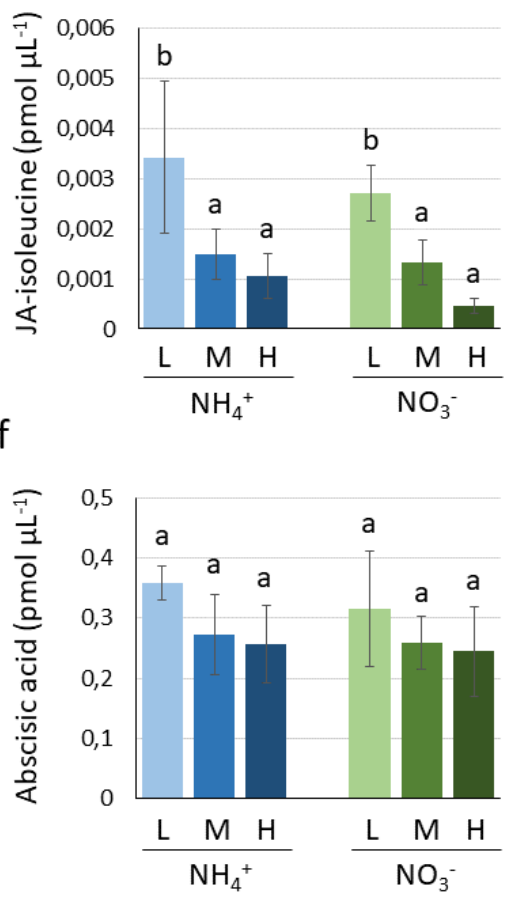

Figure 2: Phytohormone concentrations in Populus $x$ canescens xylem saps. a) Salicylic acid (SA), b) SAglucoside (SAG), c) Jasmonoyl-isoleucine (JA-lle), d) Pipecolic acid, e) $\mathrm{N}$-hydroxypipecolic acid (NHP), f) Abscisic acid (ABA). Additional phytohormones identified in xylem sap are listed in supplemental Table S3. Xylem saps were collected three weeks after feeding poplar with $\mathrm{L}(0.4 \mathrm{mM}), \mathrm{M}(2.0 \mathrm{mM})$ or $\mathrm{H}(8.0$ $\mathrm{mM}$ ) ammonium or nitrate in the nutrient solution. n.d. = not detected. Data were $\log _{2}$ transformed to achieve homogeneity of variance for statistical analyses. Bars show means $( \pm S D)$ per treatment. Different letters above the bars indicate significant differences at $p \leq 0.05$ according to Tukey's-Kramer post-hoc test, $n=5$ to 6 per treatment. 


\section{3}
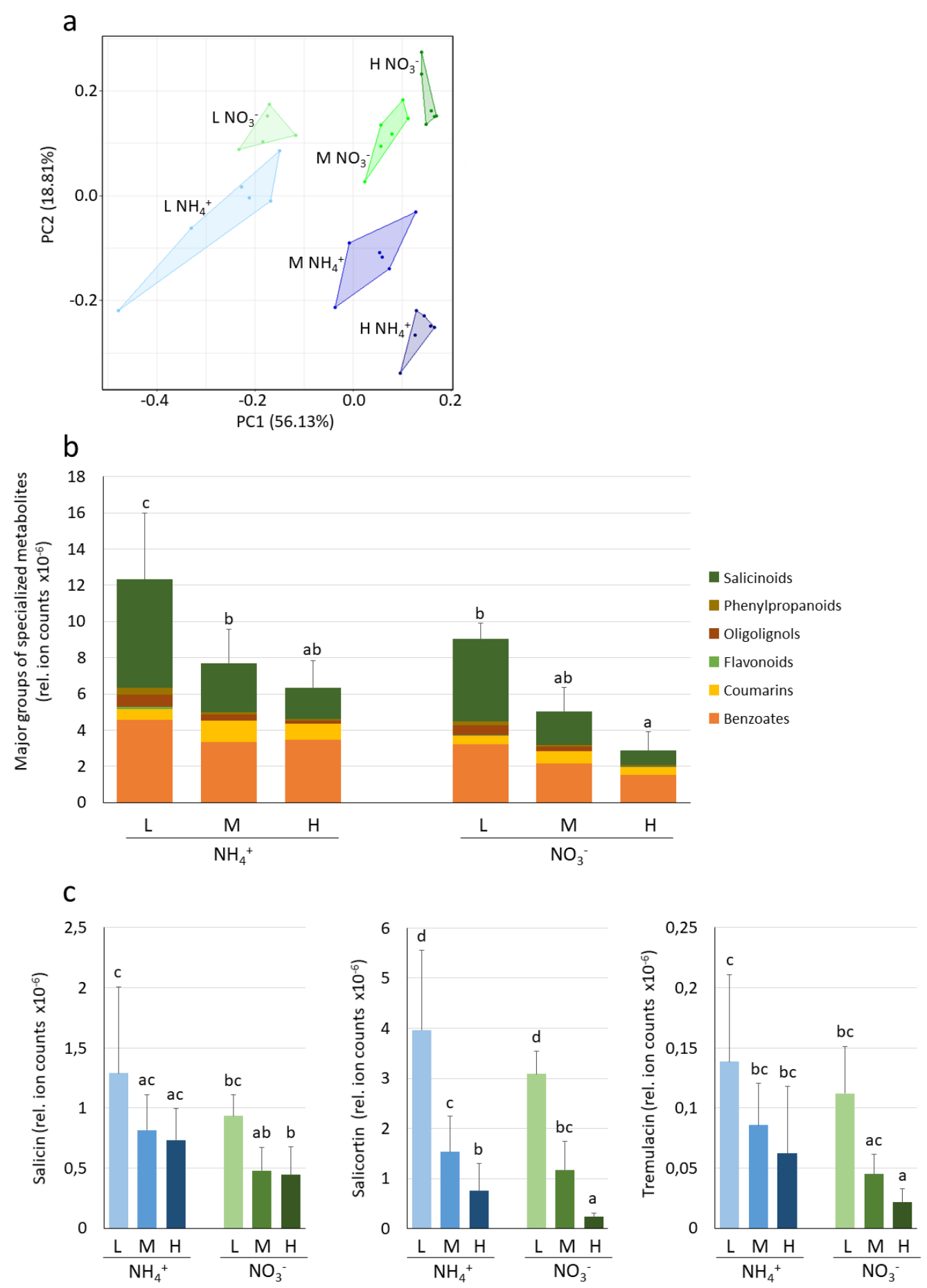

Figure 3: Specialized metabolite profiles in Populus $x$ canescens xylem saps. a) Principal component analysis of 863 metabolite features of a non-targeted metabolome approach (metabolite fingerprinting) with FDR $<10^{-6}$, b) Relative signal intensities of the major specialized metabolite classes, c) Relative signal intensities of three major salicinoid compounds. Xylem saps were collected three weeks after feeding poplar with $\mathrm{L}(0.4 \mathrm{mM}), \mathrm{M}(2.0 \mathrm{mM})$ or $\mathrm{H}(8.0 \mathrm{mM})$ ammonium or nitrate in the nutrient solution. Data were $\log _{2}$ transformed to achieve homogeneity of variance for statistical analyses and show means ( \pm SD) per treatment of five to six biological replicates. Compounds present two independent experiments (Supportive Figure S3) were included. Different letters above the bars indicate significant differences at $p \leq 0.05$ according to Tukeys-Kramer post-hoc test. 
bioRxiv preprint doi: https://doi.org/10.1101/2021.05.28.446139; this version posted May 28, 2021. The copyright holder for this preprint (which was not certified by peer review) is the author/funder, who has granted bioRxiv a license to display the preprint in perpetuity. It is made available under aCC-BY-NC-ND 4.0 International license.

\section{4}

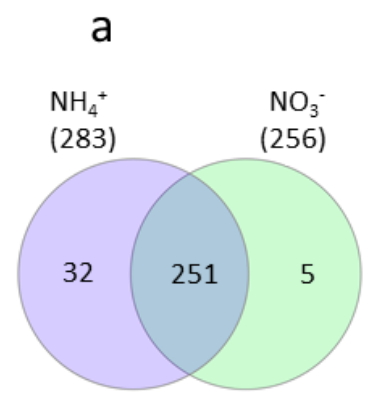

b

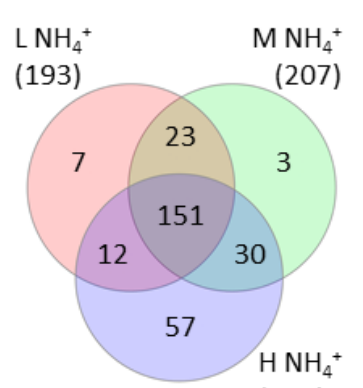

(250)

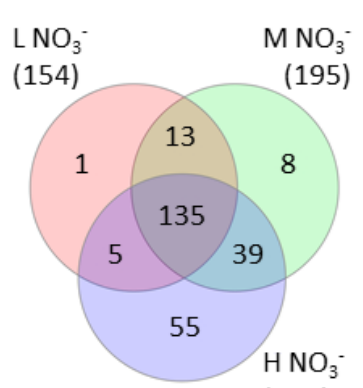

(234)

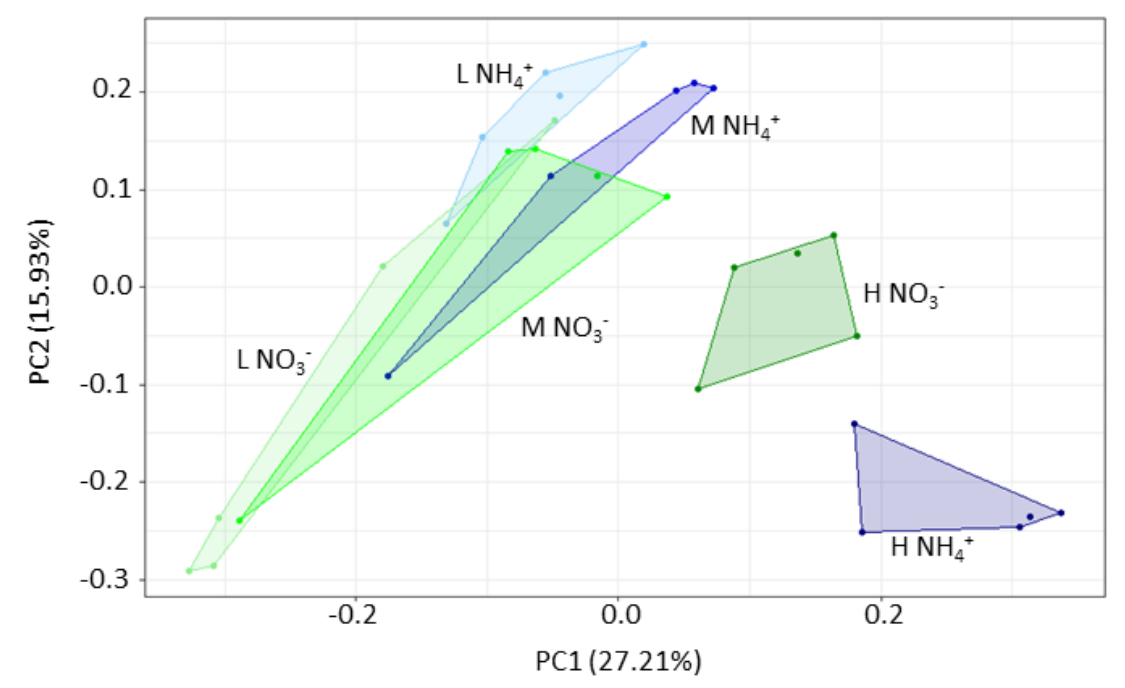

C

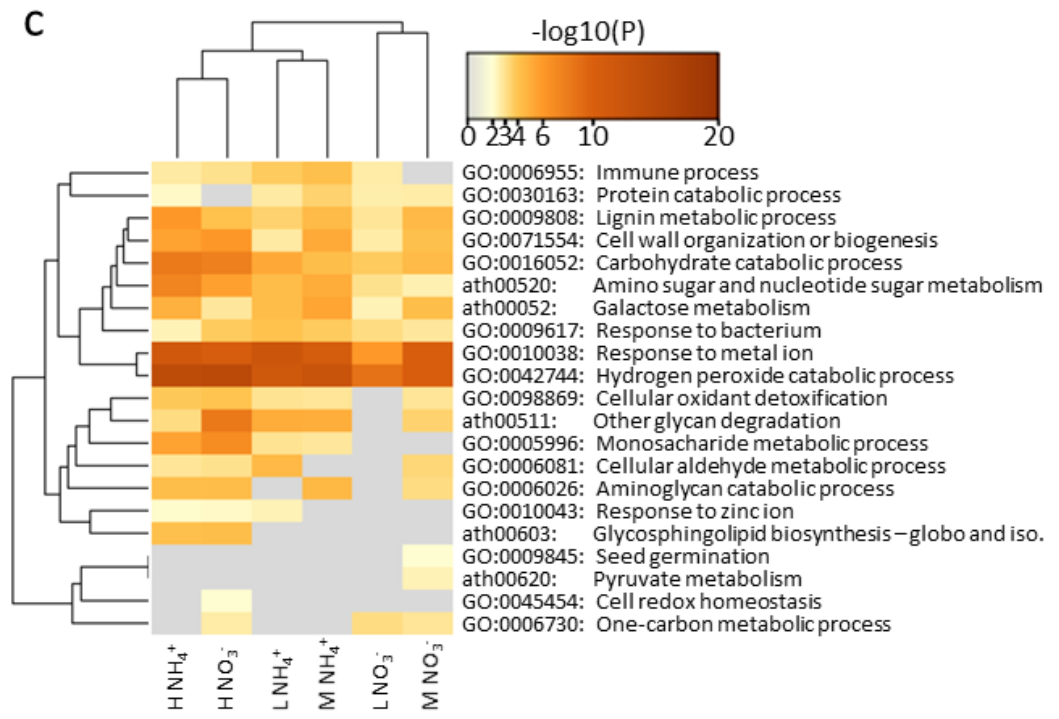

Figure 4: Proteome composition in Populus $x$ canescens xylem saps. a) Venn diagrams showing numbers of unique and overlapping proteins in xylem sap of plants supplied with supplied with low (L), intermediate (M) or high ( $\mathrm{H}) \mathrm{NH}_{4}{ }^{+}$or $\mathrm{NO}_{3}{ }^{-}$, b) Principal component analysis of the proteins in the xylem sap from different $\mathrm{N}$ treatments, $\mathrm{c}$ ) Hierarchical cluster analysis of significantly enriched gene ontology terms and KEGG pathways of poplar xylem sap proteins. Analyses were conducted with the best AGI matches of the poplar proteins and standard settings in Metascape. Xylem saps were collected three weeks after feeding poplar with $\mathrm{L}(0.4 \mathrm{mM}), \mathrm{M}(2.0 \mathrm{mM})$ or $\mathrm{H}(8.0 \mathrm{mM})$ ammonium or nitrate in the nutrient solution. Proteins present in 10 or more percent of samples were used for analyses. $n=5$ per treatment. 


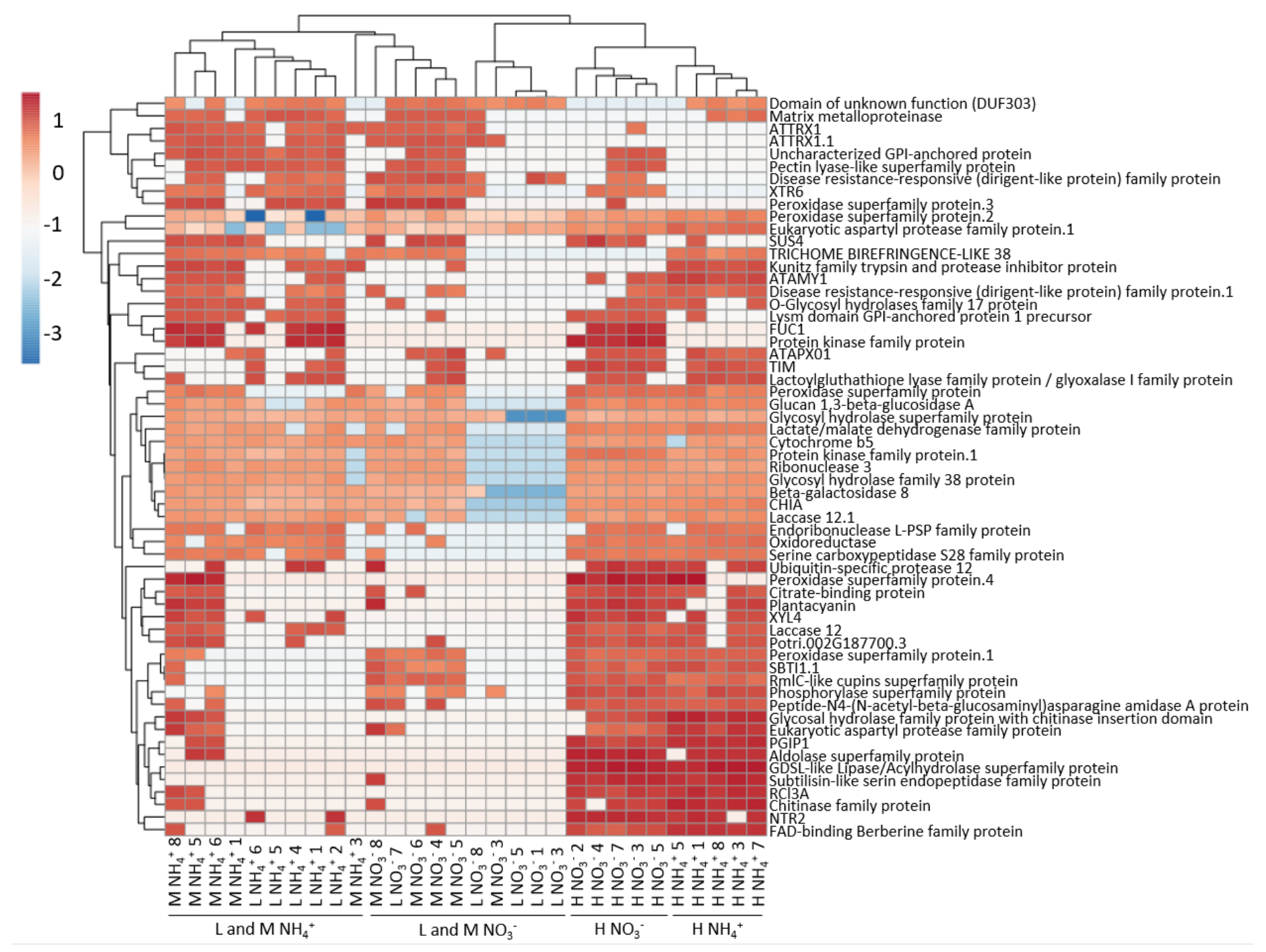

Figure 5: Hierarchical cluster analysis of 59 xylem sap proteins with significantly different abundances between nitrogen treatments. The analysis was generated with ClustVis and standard settings. Populus $x$ canescens xylem saps were collected three weeks after feeding poplars with L (0.4 mM), $\mathrm{M}(2.0 \mathrm{mM})$ or $\mathrm{H}(8.0 \mathrm{mM})$ ammonium or nitrate in the nutrient solution. $n=5$ per treatment. 
bioRxiv preprint doi: https://doi.org/10.1101/2021.05.28.446139; this version posted May 28, 2021. The copyright holder for this preprint (which was not certified by peer review) is the author/funder, who has granted bioRxiv a license to display the preprint in perpetuity. It is made available under aCC-BY-NC-ND 4.0 International license.

\section{6}

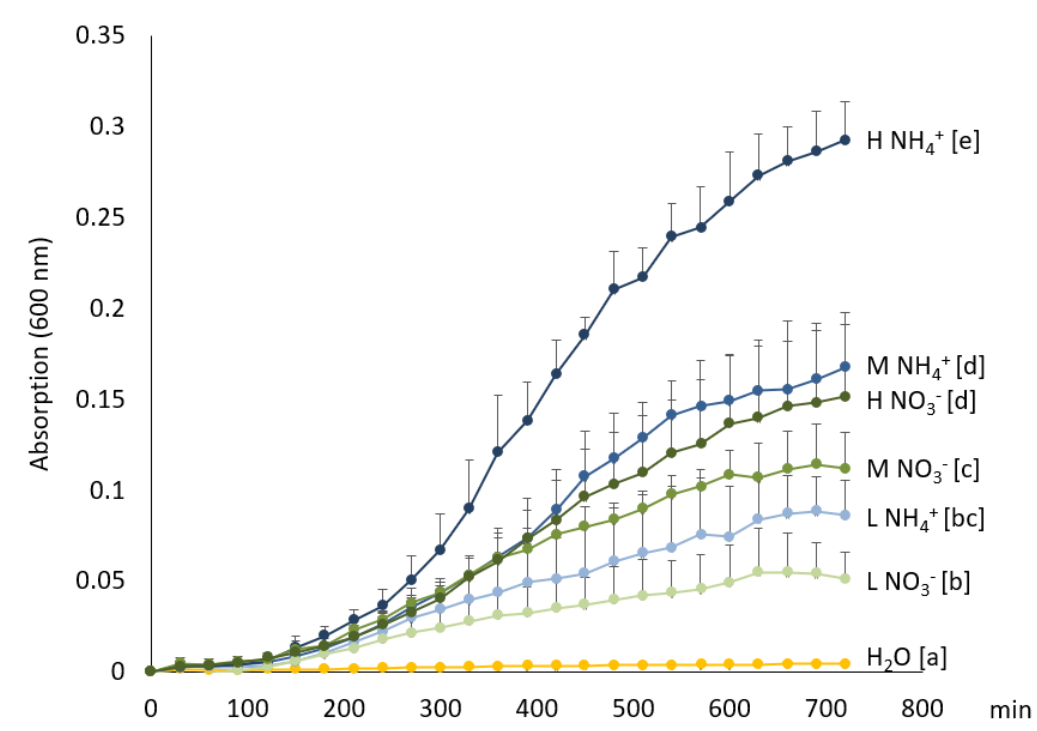

Figure 6: Brennaria salicis growth in xylem sap of Populus $x$ canescens. Populus $x$ canescens $x y l e m$ saps were collected three weeks after feeding poplars with $L(0.4 \mathrm{mM}), \mathrm{M}(2.0 \mathrm{mM})$ or $\mathrm{H}(8.0 \mathrm{mM})$ ammonium or nitrate in the nutrient solution. Aliquots of xylem sap of eight biological replicates per treatment were inoculated with B. salicis or water (control) and the increase in the optical density was determined for $12 \mathrm{~h}$. Different letters in () indicate significant differences at $p \leq 0.05$ according to Tukey's post-hoc test. Data are means $(n=8 \pm S D)$. 

made available under aCC-BY-NC-ND 4.0 International license.

\section{7}

a
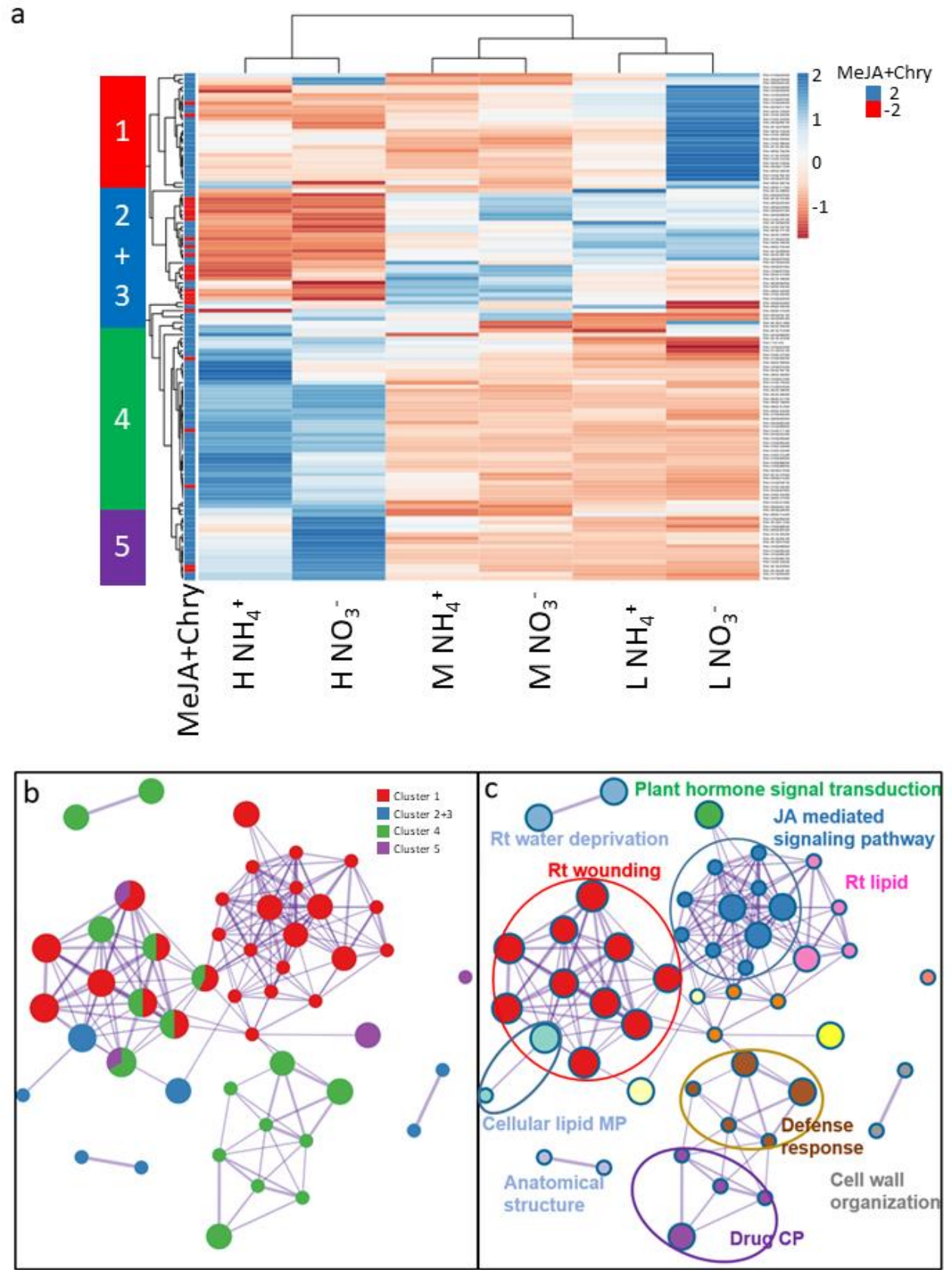

Figure 7: Cluster and network analyses of a set of shared differentially expressed genes (DEGs) in leaves of Populus $\mathrm{x}$ canescens exposed to different nitrogen and DEGs responding to application of methyl jasmonate (MeJA) and herbivory. DEGs for MeJA and herbivory by poplar leaf beetle (Chrysomela populi $=$ Chry) were extracted from published studies (Kaling et al., 2018; Luo et al., 2019). a) hierarchical cluster analysis visualizing the pattern of the N-responsive DEGs. MeJA+Chry indicate positive (blue) or negative (red) response of DEGs to MeJA treatment or herbivory. The stacked bar on the left-hand side shows a color code for the five main clusters, b) enrichment network of DEGs within clusters of same color, c) biological processes assigned to DEGs shown in b. Leaves for transcriptome analyses were collected three weeks after feeding poplar with Low (0.4 mM), Medium (2.0 mM) or High $(8.0 \mathrm{mM})$ ammonium or nitrate in the nutrient solution. Bioinformatic analysis were conducted with the best AGI match to the poplar IDs and the standard settings in Metascape. $\mathrm{CP}=$ catabolic process, $\mathrm{JA}=$ jasmonic acid, $\mathrm{MP}=$ metabolic process, $\mathrm{Rt}=$ response to. $\mathrm{n}=4$ to 5 per treatment. 
bioRxiv preprint doi: https://doi.org/10.1101/2021.05.28.446139; this version posted May 28, 2021. The copyright holder for this preprint (which was not certified by peer review) is the author/funder, who has granted bioRxiv a license to display the preprint in perpetuity. It is made available under aCC-BY-NC-ND 4.0 International license.

\section{8}

a
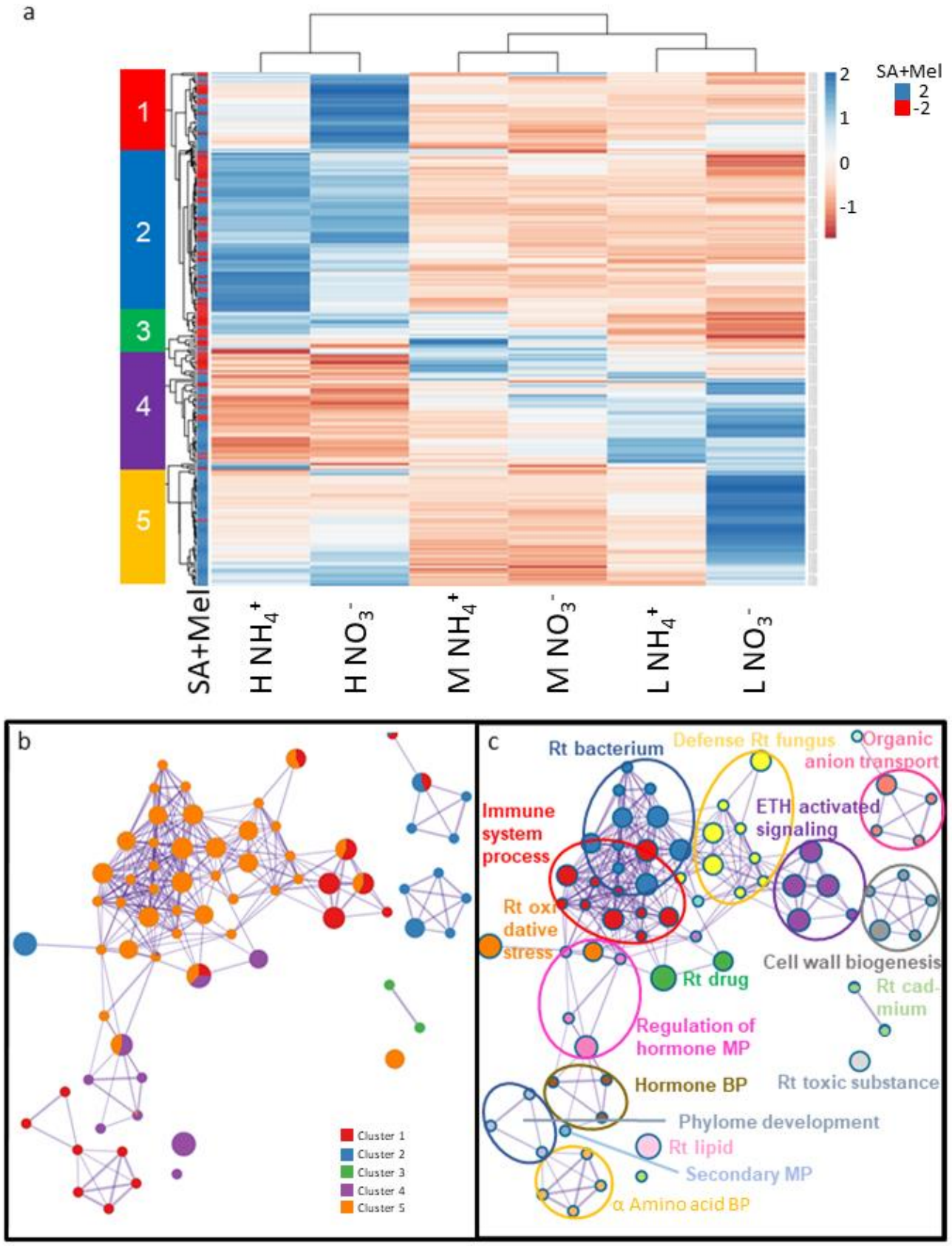

Figure 8: Cluster (a) and network analyses $(b, c)$ of a set of shared differentially expressed genes (DEGs) in leaves of Populus $x$ canescens exposed to different nitrogen and DEGs responding to application of salicylic acid (SA) and infection with rust fungi (Melampsora spp. = Mel). DEGs for SA and Mel responses were extracted from published studies (Luo et al., 2019; Miranda et al., 2007; Rinaldi et al., 2007). a) hierarchical cluster analysis visualizing the pattern of the $\mathrm{N}$-responsive DEGs. MeJA+Chry indicate positive (blue) or negative (red) response of DEGs to SA and Mel treatments. The stacked bar on the left-hand side shows a color code for the five main clusters, b) enrichment network of DEGs within clusters of same color, c) biological processes assigned to DEGs shown in b. Leaves for transcriptome analyses were collected three weeks after feeding poplar with Low (0.4 mM), Medium (2.0 mM) or High $(8.0 \mathrm{mM})$ ammonium or nitrate in the nutrient solution. Bioinformatic analysis were conducted with the best AGI match to the poplar IDs and the standard settings in Metascape. BP = biological process, $\mathrm{CP}=$ catabolic process, $\mathrm{ETH}=$ ethylene, $\mathrm{MP}=$ metabolic process, $\mathrm{Rt}=$ response to, $\mathrm{n}=4$ to 5 per treatment. 